\title{
Structural and functional conservation of non-lumenized lymphatic endothelial cells in the mammalian leptomeninges
}

\author{
Shannon Shibata-Germanos ${ }^{1}$. James R. Goodman ${ }^{2,3} \cdot$ Alan Grieg $^{1} \cdot$ Chintan A. Trivedi ${ }^{1} \cdot$ Bridget C. Benson $^{4,5}$. \\ Sandrine C. Foti ${ }^{4,5} \cdot$ Ana Faro $^{1} \cdot$ Raphael F. P. Castellan $^{7} \cdot$ Rosa Maria Correra $^{7}$. Melissa Barber ${ }^{1}$. \\ Christiana Ruhrberg ${ }^{7} \cdot$ Roy O. Weller ${ }^{8} \cdot$ Tammaryn Lashley $^{4,5} \cdot$ Jeffrey J. Iliff $^{2,6} \cdot$ Thomas A. Hawkins $^{1} \cdot$ Jason Rihel $^{1}$ (D)
}

Received: 8 June 2019 / Revised: 24 October 2019 / Accepted: 29 October 2019 / Published online: 6 November 2019

(C) The Author(s) 2019

\begin{abstract}
The vertebrate CNS is surrounded by the meninges, a protective barrier comprised of the outer dura mater and the inner leptomeninges, which includes the arachnoid and pial layers. While the dura mater contains lymphatic vessels, no conventional lymphatics have been found within the brain or leptomeninges. However, non-lumenized cells called Brain/Mural Lymphatic Endothelial Cells or Fluorescent Granule Perithelial cells (muLECs/BLECs/FGPs) that share a developmental program and gene expression with peripheral lymphatic vessels have been described in the meninges of zebrafish. Here we identify a structurally and functionally similar cell type in the mammalian leptomeninges that we name Leptomeningeal Lymphatic Endothelial Cells (LLEC). As in zebrafish, LLECs express multiple lymphatic markers, containing very large, spherical inclusions, and develop independently from the meningeal macrophage lineage. Mouse LLECs also internalize macromolecules from the cerebrospinal fluid, including Amyloid- $\beta$, the toxic driver of Alzheimer's disease progression. Finally, we identify morphologically similar cells co-expressing LLEC markers in human post-mortem leptomeninges. Given that LLECs share molecular, morphological, and functional characteristics with both lymphatics and macrophages, we propose they represent a novel, evolutionary conserved cell type with potential roles in homeostasis and immune organization of the meninges.
\end{abstract}

Keywords Meningeal lymphatics $\cdot$ Lymphatics $\cdot$ Macrophages $\cdot$ CNS macrophages $\cdot$ CNS lymphatics

\section{Introduction}

The brain is surrounded by the meninges, a trilaminar compartment comprised of an outer dura mater, a middle arachnoid mater, and an inner layer of pia mater. The meninges

Electronic supplementary material The online version of this article (https://doi.org/10.1007/s00401-019-02091-z) contains supplementary material, which is available to authorized users.

Jason Rihel

j.rihel@ucl.ac.uk

1 Department of Cell and Developmental Biology, University College London, London WC1E 6BT, UK

2 Department of Anaesthesiology and Perioperative Medicine, Oregon Health \& Science University, Portland, OR, USA

3 Department of Physiology and Pharmacology, Oregon Health \& Science University, Portland, OR, USA

4 The Queen Square Brain Bank for Neurological Disorders, Department of Clinical and Movement Neurosciences, UCL Institute of Neurology, London, UK not only serve as a protective physical barrier for the central nervous system (CNS) but also participate in the immune surveillance and fluid homeostasis of the cerebrospinal fluid (CSF), which fills the subarachnoid space between the pia and arachnoid layers (collectively known as the leptomeninges). Under steady-state conditions, the meninges are replete with immune cells including macrophages, mast cells, B cells, and $\mathrm{T}$ cells that protect the brain from infection and

5 Department of Neurodegenerative Disease, UCL Institute of Neurology, London, UK

6 Knight Cardiovascular Institute, Oregon Health \& Science University, Portland, OR, USA

7 UCL Institute of Ophthalmology, University College London, London, UK

8 Clinical Neurosciences (Neuropathology), Faculty of Medicine, Southampton University Hospitals, Southampton SO16 6YD, UK 
are capable of mounting a rapid and strong neuroinflammatory response. Most CNS immune responses first start within the meninges [51], and meningeal inflammation impacts a variety of diseases, including multiple sclerosis, meningitis, various forms of dementia pathology, stroke, and migraine $[7,14,44]$. Thus, understanding the mechanisms by which the meninges interact with the brain and surrounding CSF during both steady-state and diseased conditions have important clinical and therapeutic implications.

In peripheral tissues, the maintenance of fluid homeostasis is aided by a network of lymphatic vessels that drains fluid and metabolic waste from surrounding tissue and participates in immunity by trafficking leukocytes and $\mathrm{T}$ cells $[24,27]$. The fibrous outer dura mater of the meninges also contain a lymphatic vascular network lining the venous sinuses [5, 38], and a network of meningeal lymphatic vessels at the base of the skull have recently been described [1, $4,5]$. There is some evidence that dorsal dural lymphatic vessels are capable of draining macromolecules from the CSF [5, 38]. However, other reports fail to detect CSF drainage into dorsal dural lymphatics and suggest alternative drainage routes, such as along blood vessels or olfactory nerves or within lymphatic vessels that pass through the cribriform plate, or into the ventral dural lymphatics at the base of the skull [1, 23, 28, 31, 39, 45]. Dorsal dural lymphatics can also transport immune cells from the meninges and modulate T-cell activation during inflammation, and ablation studies of the dorsal dural lymphatics have demonstrated the importance of these vessels in the promotion of neuroinflammatory responses in an animal model of multiple sclerosis [37]. Moreover, dorsal dural lymphatic deletion studies suggest they also participate in the drainage of waste from the CSF, including amyloid- $\beta$, which forms hallmark extracellular protein aggregates in Alzheimer's disease [1, 44]. In contrast, enhancing dorsal dural lymphatic drainage of aged mice improved brain clearance and cognitive performance [44], highlighting the untapped therapeutic potential of targeting dural lymphatic function in age and disease.

In contrast to the dura mater, the brain and leptomeninges have never been reported to contain lymphatic vessels. However, a previously undescribed cell type, variously called Brain Lymphatic Endothelial Cells (BLECs), mural LECs (muLECs), or Fluorescent Granule Perithelial Cells (FGPs), that share numerous features of lymphatic endothelium was recently identified in zebrafish $[11,36,66]$. Under normal conditions, BLECs do not lumenize to form vessels but exist as single cells in close association with meningeal blood vessels [11, 36, 66]. However, BLECs do have other molecular, developmental, and functional features of peripheral lymphatic vessels. BLECs express numerous lymphatic endothelial genes, such as the lymphatic markers prospero homeobox domain protein la (proxla) [26, 69] vascular endothelial growth factor receptor 3 (vegfr 3 ; also known as fms-related tyrosine kinase 4, or ftt4) and the lymphatic vessel endothelial hyaluronan receptor 1 (lyve1). Like peripheral lymphatics, BLECs sprout from the venous endothelium and require lymphatic developmental signals such as Collagen and calcium binding EGF domains 1 (Ccbe1) [22], but not the macrophage transcription factor pU.1, to properly form. Functionally, BLECs can internalize macromolecules from the brain in a Mannose Receptor 1a (Mrc1a)-dependent manner $[36,66]$ and can remove lipids from the blood [11]. They are also important for the proper development of neighbouring meningeal blood vessels [11]. Overall, these data support the view that zebrafish BLECs are a type of lymphatic endothelial cell that reside in the meninges.

Whether BLECs are a fish-specific meningeal cell type or are also present in the leptomeninges of mammals remains an open question. To test whether BLECs are evolutionarily conserved, we examined the expression of BLEC proteins in mouse and human leptomeninges using both confocal and electron microscopy. We discovered cells in both mouse and human that have morphological, ultrastructural, and molecular features of BLECs. As in zebrafish, these cells rapidly internalized macromolecules, including $A \beta$. To emphasize their evolutionary conservation, lymphatic molecular and functional character, and location within the subarachnoid space, we propose to call this novel mammalian cell type Leptomeningeal Lymphatic Endothelial Cells (LLECs).

\section{Materials and methods}

\section{Animals}

\section{Zebrafish}

Zebrafish experiments followed guidelines of the animal ethics committees at University College London and were performed in accordance with the UK Animal (Scientific Procedures) Act 1986 under project licences awarded to J.R. and Steve Wilson. The following transgenic and mutant lines were used in this study:

\begin{tabular}{ll}
\hline Transgenic line & References \\
\hline $\operatorname{Tg}(k d r-l: H R A S-m C h e r r y-C A A X)^{s 916}$ & {$[22]$} \\
$\operatorname{Tg}\left(\text { flt }{ }^{B A C}: \text { } m \text { Citrine }\right)^{\text {hu7135 }}$ on casper background & {$[26]$} \\
$\operatorname{Tg}($ mpeg1:Gal4-FF $)$ gl25; $T g(U A S-E 1 b: n f s B$. & {$[67]$} \\
mCherry $)^{c 264}$ on nacre ${ }^{-/-}$background & \\
\hline
\end{tabular}

Embryos, larval and adult zebrafish (Danio rerio) were kept in University College London's fish facility at $28^{\circ} \mathrm{C}$ with a $14 \mathrm{~h}$ light and $10 \mathrm{~h}$ dark cycle and were fed a diet mix of Safe (bernaqua) Caviar 500-800, Micro Gemma 500, Hikari micro pellets in a mix of 3 to 2 to 1 . 


\section{Mouse}

Mouse experiments followed the guidelines of either the animal ethics committees at University College London under project licences awarded to John Parnavelas, Christiana Ruhrberg, Francis Edwards, and Steven Hunt under the UK Animal (Scientific Procedures) Act 1986, or the Institutional Animal Care and Use Committee of Oregon Health \& Science University (Jeff Iliff).

The following mouse lines were used in this study:

\begin{tabular}{ll}
\hline Line & References \\
\hline C57B1/6 & Jackson Laboratories \\
Tie2-GFP;NG2-DSRed & {$[25]$} \\
Spi $1^{\text {tmlRam }}$ & $(\mathrm{PU} .1) ;[43]$ \\
GAD67-GFP+ve $(\Delta n e o)$ & {$[59]$} \\
AKR background & {$[21]$} \\
\hline
\end{tabular}

\section{Breeding}

For Fig. 3, wild type embryos were obtained from time-mated GAD67-GFP + ve ( $\Delta$ neo) [59] mice, maintained in a C57bl/6J background at Biological Services UCL and GFP-ve embryos were used. For Fig. 4, Spi1 ${ }^{\text {tm1Ram }}$ (referred to as PU.1 ${ }^{-1-}$ ) [43] transgenic mice and WT controls were maintained on a mixed background (C57B16/J;129/Sv). In both experiments, the day of the vaginal plug was considered E0.5.

PU.1 KO mice and wildtype siblings were genotyped as follows:

\begin{tabular}{lllllll}
\hline Line & $\begin{array}{c}\text { OLI- } \\
\text { GOS }\end{array}$ & Notes & $T{ }^{\circ} \mathrm{C}$ & WT bp & MUT bp & $\begin{array}{c}\text { MUT } \\
\text { band }\end{array}$ \\
\hline Spi1 $^{\text {tm1Ram }}$ & KO2 & $\begin{array}{c}\text { dowt } \\
\text { and } \\
\text { mut }\end{array}$ & 60 & 1237 & 980 & $\begin{array}{c}\text { Bot- } \\
\text { tom }\end{array}$ \\
Spi1 $1^{\text {tm1Ram }}$ & 920 & $\begin{array}{c}\text { pcrs } \\
\text { sepa- } \\
\text { rately }\end{array}$ & KO2+920 & KO2+Neo2 & \\
Spi1 ${ }^{\text {tm1Ram }}$ & Neo2 & & & & & \\
\hline
\end{tabular}

\begin{tabular}{lll}
\hline PCR & OLIGOS & Sequence $\left(5^{\prime}-3^{\prime}\right)$ \\
\hline Spi $^{\text {tm1Ram }}$ & KO2 & GCCCCGGATGTGCTTCCCTTATCAAAC \\
Spi $^{\text {tm1Ram }}$ & 920 & TGCCTCGGCCCTGGGAATGTC \\
${\text { Spi }{ }^{\text {tm1Ram }}}^{\text {Neo2 }}$ & CGCACGGGTGTTGGGTCGTTTGTTCGG \\
\hline
\end{tabular}

\section{Electron microscopy}

\section{Zebrafish}

Adult zebrafish were killed by terminal anaesthesia followed by cardiac perfusion with either $2 \%$ paraformaldehyde/2\% EM-grade glutaraldehyde in $0.1 \mathrm{M}$ sodium cacodylate buffer $\mathrm{pH} 7.3$ for conventional electron microscopy (EM) or $4 \%$ paraformaldehyde (PFA) in $0.1 \mathrm{M}$ phosphate buffer pH7.3 (PB) for immunoEM. For conventional EM, brains were cut into chunks, postfixed in osmium tetroxide and embedded in epoxy (agar100 resin, Agar Scientific) before sectioning and staining with lead citrate. For postembed immunoEM, sections were embedded in LR-white resin, followed by sectioning, mounting on nickel grids, blocking in normal goat serum (NGS) and incubation with polyclonal rabbit anti-GFP primary antibody (TP401; Amsbio) followed by anti-rabbit $20 \mathrm{~nm}$ gold-labelled secondary (TAAB GBL024/1).

\section{Mouse}

Founder C57BL/6j mice were purchased from Charles River and male offspring were bred and maintained at UCL on a 12-h light/12-h dark cycle with ad libitum supply of food (Envigo 2018 Teklad global 18\% protein rodent diet) and water. Mice were deeply anaesthetised with Euthatal then transcardially perfused with heparinised (5000 U/1) physiological saline, followed by $4 \%$ PFA in $\mathrm{PB}$ pH 7.3 prepared fresh on day of perfusion. Following this, brains were dissected and postfixed by immersion in the same fixative mix overnight at $4{ }^{\circ} \mathrm{C}$. Immunohistochemistry was carried out in PB on floating $100 \mu \mathrm{m}$ coronal vibratome sections using rabbit anti-LYVE1 antibody (11-034, Angiobio). Nanogold (1.4 nm; Nanoprobes) goat antirabbit secondary was used and detected using HQ silver enhancement kit (Nanoprobes) following manufacturer's instructions before postfixation using 1\% EM-grade glutaraldehyde and conventional epoxy-based EM processing and sectioning. Ultrathin sections were stained lightly for contrast using lead citrate.

\section{EM imaging}

Both zebrafish and mouse sections were examined using JEOL1010 microscope with a Gatan Orius camera. The 32 bit digital image files (*.dm3) were processed using FijiImageJ with minimal contrast adjustments and scale bar additions. Pseudo colouring, thresholding (to highlight gold/ silver labelling), and other labelling was carried out using Adobe Photoshop. 


\section{Auto-fluorescence inclusion check}

\section{Zebrafish}

5-month-old WT AB zebrafish fed a diet mix of Safe (bernaqua) Caviar 500-800, Micro Gemma 500, Hikari micro pellets in a mix of 3-to-2-to-1, were terminally anaesthetized in MS222 (Sigma, \#A5040) and brain dissected in ice cold $0.1 \%$ phosphate buffered saline (PBS). Dissected brains were first examined in a petri dish on an epifluorescence microscope, and then placed in a $4 \%$ paraformaldehyde $/ 4 \%$ sucrose solution $\mathrm{O} / \mathrm{N}$ at $4{ }^{\circ} \mathrm{C}$. Brains were then washed $3 \times$ in PBS before mounting in 2\% low-melting agarose (ThermoFischer, \#16520100) dissolved in PBS within glass rings that were then cover-slipped.

\section{Mouse}

Founder C57BL/6j mice were purchased from Charles River and male offsprings were bred and maintained at UCL on a 12-h light/12-h dark cycle with ad libitum supply of food (Envigo 2018 Teklad global 18\% protein rodent diet) and water. Mice were deeply anaesthetised with Euthatal then transcardially perfused with heparinised (5000 U/l) physiological saline, followed by 4\% PFA in PBS, prepared fresh on day of perfusion. Freshly dissected brains of 5-month-old mice were immersed in 4\% PFA/PBS, incubated for $2 \mathrm{~h}$ at $4{ }^{\circ} \mathrm{C}$ on ice, washed twice with PBS and then immersed in $30 \%$ sucrose/PBS and kept at $4{ }^{\circ} \mathrm{C}$. Brains were then washed $3 \times$ in PBS before mounting in $2 \%$ low-melting agarose (ThermoFischer, \#16520100) dissolved in PBS within glass rings that were then cover-slipped.

\section{Auto-fluorescence imaging}

Images were obtained from an Olympus MVX10 with a standard GFP bandpass at $6 \times$ and after fixation with a Leica DM LB epi-fluorescence microscope with a DFC310 FX camera and standard GFP ex/em bandpass filter cube with $10 \times-60 \times$ air lenses. A Leica SP8 LSCM was then utilised with a $10 \times$ dry lens and $25 \times$ water immersion lens, applying a 500-588 $\mathrm{nm}$ bandpass and exciting with a $488 \mathrm{~nm}$ argon laser and zoom of 0.75 and 3 .

\section{Fluorescent in situ hybridization}

Founder C57BL/6j mice were purchased from Charles River and male offspring were bred and maintained at UCL on a 12-h light/12-h dark cycle with ad libitum supply of food (Envigo 2018 Teklad global 18\% protein rodent diet) and water. Mice were deeply anaesthetised with Euthatal then transcardially perfused with heparinised (5000 U/l) physiological saline, followed by $10 \%$ formalin solution $(4 \%$
PFA in PBS, prepared fresh on day of perfusion). Freshly dissected brain hemispheres of 5 month-old mice were immersed in 4\% PFA/PBS (all PBS was DEPC treated) solution, incubated for $24 \mathrm{~h}$ at $4{ }^{\circ} \mathrm{C}$, washed twice with PBS and then immersed in $30 \%$ sucrose/PBS for $1-2$ days at $4{ }^{\circ} \mathrm{C}$. Fixed brain tissue was then washed twice in PBS, frozen in pre-cooled isopentane (2-methylbutane, Sigma-Aldrich) on dry ice and stored at $-80^{\circ} \mathrm{C}$. Frozen brain hemispheres were embedded in OCT and $30 \mu \mathrm{m}$ coronal sections were cut on a Leica CM1850 cryostat.

Digoxigenin and fluorescein-labelled probes were made via standard protocols, amplified by PCR from cDNA using primer pairs found on Allen Mouse Brain Atlas [34] as described below.

The in situ hybridization protocol was adapted from a previous published protocol [3] with the following modifications:

\begin{tabular}{|c|c|c|c|}
\hline Gene name & Forward pair & $\begin{array}{l}\text { Reverse primer } \\
\text { (with } \underline{\mathrm{T} 3} \\
\underline{\text { sequence) }}\end{array}$ & Probe length \\
\hline Vegfr3 & $\begin{array}{c}\text { 5'CAAGAC } \\
\text { CTGCTT } \\
\text { TCTCTG } \\
\text { ACCT-3' }\end{array}$ & $\begin{array}{c}\text { 5'AATTAACCC } \\
\text { TCACTAAAG } \\
\text { GGTCCTGGA } \\
\text { TATGGAGGC } \\
\text { TGTAGT-3' }\end{array}$ & $763 \mathrm{bp}$ \\
\hline Proxl & $\begin{array}{c}\text { 5'TATATA } \\
\text { TTTGTG } \\
\text { TGGGGG } \\
\text { AGGC-3' }\end{array}$ & $\begin{array}{l}\text { 5'AATTAACCC } \\
\text { TCACTAAAG } \\
\text { GGGCAACTA } \\
\text { GTGACAAAG } \\
\text { CACAGG-3' }\end{array}$ & $647 \mathrm{bp}$ \\
\hline
\end{tabular}

$30 \mu \mathrm{m}$-thick sections were transferred to a 12 -well falcon plate into PBS/Tween 20 (PBST) and washed $3 \times 10$ min to remove sucrose. Brain sections were pre-hybridised overnight in hybridization solution at $60{ }^{\circ} \mathrm{C}$, in a hybridization oven gently rocking until the sections sank. The following day riboprobes were pre-heated in blocks to $80^{\circ} \mathrm{C}$ for $10 \mathrm{~min}$ prior to being mixed in hybridization buffer, at a final concentration of $100-300 \mathrm{ng} / \mu \mathrm{L}$.

Brain sections were hybridised overnight at $60{ }^{\circ} \mathrm{C}$ in a hybridization oven with gentle rocking. Probe removal was done with a series of hot washes in preheated wash solution (50\% Formamide, $1 \times \mathrm{SSC}, 0.1 \%$ Tween-20) at $65^{\circ} \mathrm{C}$ for $3 \times 1 \mathrm{~h}$. Sections were subsequently washed in Maleic Acid Buffer (100 mM Maleic Acid, pH 7.5) and blocked for at least $1 \mathrm{~h}$ at RT in blocking solution (2\% Boehringer Blocking Reagent in Maleic Acid Buffer; 11096176001, Roche). Anti-Fluorescein-POD antibody (11426346910, Sigma) was applied at 1:500 dilution in blocking solution, and incubated overnight at $4{ }^{\circ} \mathrm{C}$. Unbound antibody was subsequently removed in a series of PBST washes at RT. Detection of fluorescein-labelled riboprobes was done using as substrates the bench-made fluorescein tyramide (green) in some wells 
and $\mathrm{Cy} 3$ tyramide (red) in others, as previously described [33]. Brain sections were incubated for $20 \mathrm{~min}$ in either fluorescein tyramide (1:500) or cy3 (1:100) diluted in PBST, at RT and with gentle shaking, protect from light. $2 \mu \mathrm{L}$ of $0.5 \%$ $\mathrm{H}_{2} \mathrm{O}_{2}$ in PBST was added to $1 \mathrm{~mL}$ of the tyramide solutions for a final concentration of $0.001 \%$. The tyramide reaction ran for 40 min protected from light and without agitation. Samples were subsequently rinsed and washed $3 \times 15 \mathrm{~min}$ in PBST. Samples were then washed for 10 min each in $30 \%$, $50 \%, 75 \%$ and $100 \%$ methanol in PBST.

Sections were then incubated in a solution of $1 \% \mathrm{H}_{2} \mathrm{O}_{2}$ in methanol for $30 \mathrm{~min}$ to inactivate the first peroxidase. Samples were then rehydrated in the wells in a reverse order for 10 min each at RT then washed $2 \times$ in PBST for the removal of all traces of methanol. Brain slices were incubated in blocking buffer for $1 \mathrm{~h}$ at RT. Anti-DIG POD (11207733910, Sigma) was added into the appropriate wells with the block at $1: 1000 \mathrm{O} / \mathrm{N}$ at $4{ }^{\circ} \mathrm{C}$. The following morning samples were washed $4 \times 30 \mathrm{~min}$ in PBST at RT. Samples were washed several times in PBST and then mounted onto glass slides with coverslips using an anti-fade mounting media (CitiFluor, UK) and kept at $4{ }^{\circ} \mathrm{C}$ in the dark until imaging.

Brains from single and double fluorescent ISH were imaged on a Leica SP8 LSCM with $25 \times$ water of $63 \times$ oil immersion objectives.

\section{$A \beta$ injections and infusions}

\section{Zebrafish $A \beta$ injection}

$\mathrm{A} \beta$ injections were carried out with a Pneumatic PicoSpritzer III (Parker Instrumentation) with glass capillary needles (Harvard Apparatus \# GC100F-15) prepared with a Micropipette Puller (Sutter Instruments, \# P-87) HiLyte647-conjugated A $\beta 1-40$ (Anaspec) was constituted in PBS, diluted to $1 \mathrm{mg} / \mathrm{mL}$ and kept on ice until the point of injection. The injected embryos were anaesthetized in $2 \%$ low-melting agarose (ThermoFischer, \#16520100) dissolved in embryo medium containing $42 \mathrm{mg} / \mathrm{L}$ MS222 (Sigma, \#A5040) and injected with a total volume of $1 \mathrm{~nL}$ per injected bolus. Needles were inserted into the brain in a sloped angle into the CSF directly dorsal lateral to the posterior region of the hindbrain ventricle.

Live larval fish and whole mounts were imaged with a Leica SP8 laser scanning confocal microscope (LSCM) using $25 \times$ and $40 \times$ water immersion objectives.

\section{Mouse intracisternal tracer infusion}

For experiments involving mice, $2-6$ month old male and female C57B1/6 or NG2-DsRed mice from Jackson Laboratories were used after several days of acclimation to their home environment.
Anaesthesia was induced with $3 \%$ isoflurane and after a surgical plane was achieved, isoflurane was reduced to $1.5 \%$. Mice were placed in a 3-point stereotaxic apparatus and fur on the posterior head and cervical regions was removed with a chemical depilatory agent. Mice were placed under a heating lamp and core body temperature was monitored with a digital rectal thermometer throughout the experiment.

For intracisternal infusions, a 2-cm midline incision was made along the posterior head and neck. Skin was retracted laterally and the levator auris longus, platysma, acromiotrapezius, and splenius muscles were sectioned and reflected laterally with 6-0 braided suture to expose the atlanto-occipital membrane. The mouse's nose was lowered approximately $20^{\circ}$ and posterior longitudinal ligament was dissected to optimize visualization of the cisterna magna. A $301 / 2$ ga. needle was inserted into 12 inches of PE-10 tubing connected to a $10 \mu \mathrm{L}$ gas chromatography syringe (Hamilton). A solution of $\mathrm{A} \beta_{1-40}$ HiLyte-555 (Anaspec) or10 $\mathrm{kDa}$ Cascade blue dextran (Thermofischer D1976) was backfilled into the tubing and the bevel of the needle was inserted into the cisterna magna. Supplementary Fig. 5 was from a 1:1 co-infused solution. Placement was confirmed and $2 \mu \mathrm{L}$ of solution was infused into the cisterna magna at a rate of $1 \mu \mathrm{L}$ per minute. Mice were sacrificed 1 hour after initiation of infusion by intracardiac infusion of normal saline and $4 \%$ paraformaldehyde for fixation. After dissection of cranium, the brain tissue was gently removed, fixed in 4\% PFA overnight, and prepped for immunohistochemistry.

\section{Immunohistochemistry}

\section{Zebrafish}

Coronal cryosections of adult brains from 14 month old Tg(flt4:mCitrine); Tg(kdr-l:mCherry) fish were labelled as per [36]. Primary antibodies used were $\alpha$-RFP (1:2000, Rockland USA, \#600-901-379), $\alpha$-GFP (1:2000, Nacalai Tesque, 04404-84). Secondary antibodies used were $\alpha$-chicken Alexa Fluor 568 (1:2000, ThermoFischer, \#A11041), $\alpha$-rat Alexa Fluor 488 (1:2000, ThermoFischer, A11006). DAPI was used at 1:1000 dilution (ThermoFischer, D1306).

Zebrafish brain sections were imaged with a Zeiss Airyscan 880 LSCM using a $63 \times$ oil immersion objective and a Leica SP8 LSCM using $25 \times$ water of $63 \times$ oil immersion objectives.

\section{Mouse}

Antibodies (Figs. 1, 3, 4, 6, and Supplemental Figs. 2, 3) The primary antibodies used in most mouse IHC experiments are as follows: MR1 (1:100-200, Abcam ab64693), VEGFR3 (1:100-200, R\&D Systems, AF743), PROX1 (1:200, 

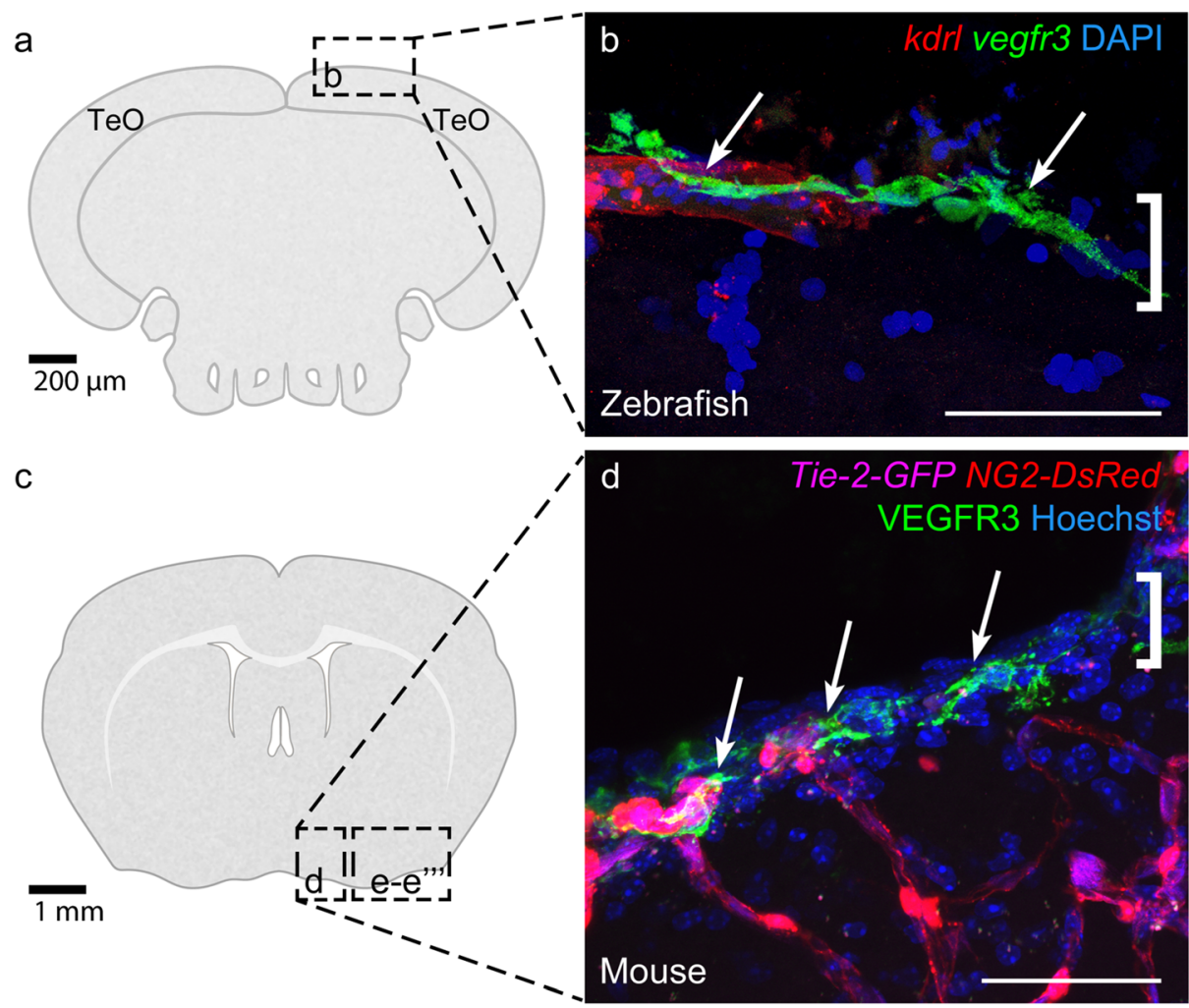

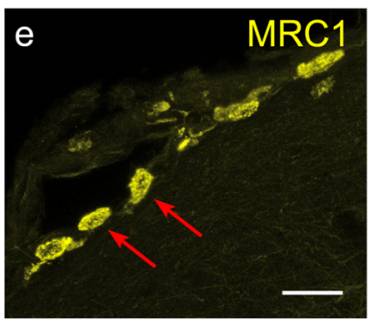

$\mathrm{f}$

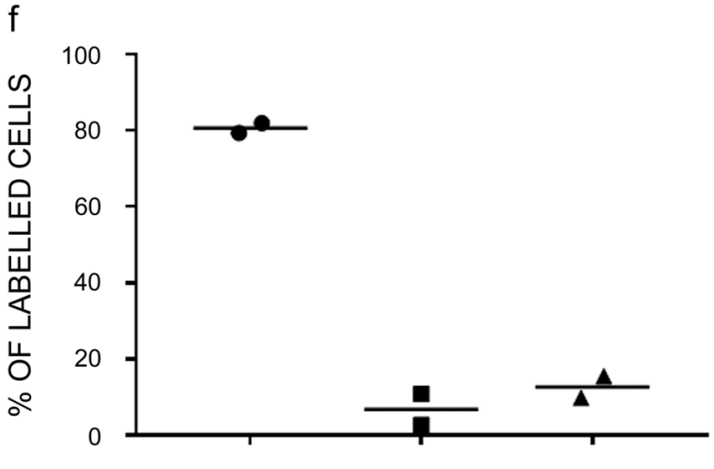

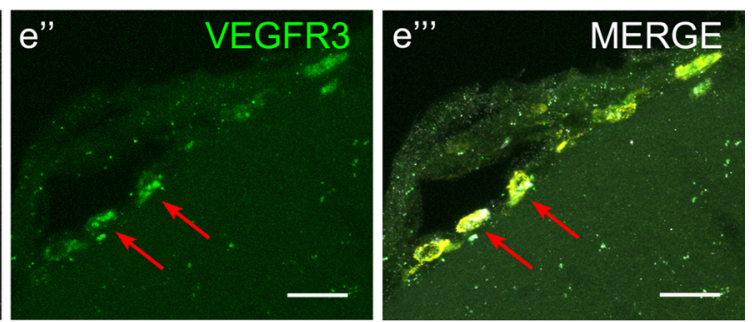

g

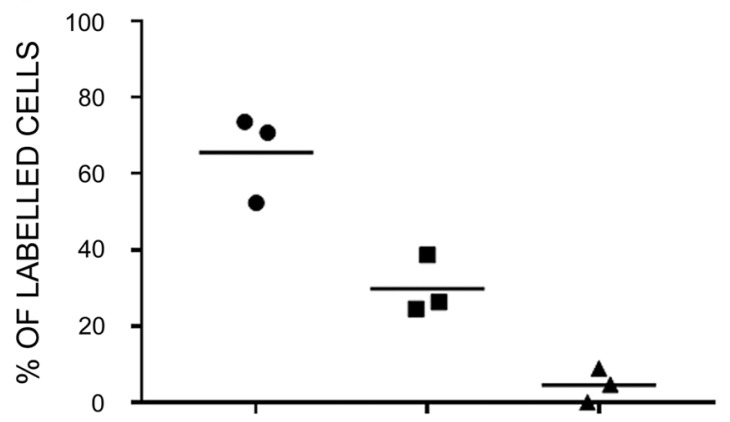

MRC1

LYVE1

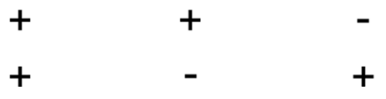

Abcam ab38692): LYVE1(1:200-1:1000 Thermofischer 14-0443-80 ALY7), MR1 (1:500 RandD AF2535). MRC1 (R\&D Systems AF2535RD), PROX1 (1:500-1000 Novus NBP1-18605), LAMININ (1:200 Chemicon AB19012MI), LYVE1 (1:200 Novus NB110-61026) PODOPLANIN (1:500, eBioscience 8.1.1 14-5381-82). The following fluorescent secondaries were applied at dilutions of 1:500: Donkey $\alpha$-Goat Alexa Fluor 633 (Invitrogen A21082), Donkey $\alpha$-Rabbit Alexa Fluor 488 (Invitrogen A21206), Donkey $\alpha$-Rat DyLight 550 (Invitrogen SA5-10027) and Goat $\alpha$-Syrian Hamster FITC, (eBioscience 11-4211-85). DAPI 
४Fig. 1 Cells with BLEC molecular markers are present within the mouse leptomeninges. a Coronal brain section of adult zebrafish brain indicating the imaging area in the dorsal optic tectum (TeO). b A 14 month old $T g(k d r$-l:mCherry); $T g$ (flt4:mCitrine) double transgenic zebrafish has cells in the meninges (white bracket) that express flt4/vegfr3 ( $\alpha$-GFP, green) near $k d r-l$ positive ( $\alpha$-RFP, red) blood vessels. DAPI (blue) labels the nuclei. Scale $=50 \mu \mathrm{m}$. c Coronal mouse brain section showing the imaging areas of the meninges. d As revealed by IHC, 17-week-old mouse brains express VEGFR3 (green) in the meninges (white bracket). Tie2-GFP;NG2-DsRed double reporter mice were used to distinguish arteries and veins. NG2 (red) labels pericytes and smooth muscle cells, Tie2 (magenta) labels vascular endothelial cells, and Hoechst (blue) stains nuclei. The image is rotated with the parenchyma at the bottom for ease of comparison with panel b. Scale $=50 \mu \mathrm{m}$. e-e"' As revealed by IHC, cells of the meninges co-express MRC1 (e, yellow), LYVE1 (e', white), and VEGFR3 ( $\mathbf{e}^{\prime \prime}$, green). Red arrows highlight cells expressing these three markers. The images are rotated with the parenchyma at the bottom. scale $=30 \mu \mathrm{m}$. $\mathbf{f}, \mathbf{g}$ Quantification of the relative numbers of single and double-labelled cells in 2-month old mouse meninges. VEGFR3 and LYVE1 cell counts were from $n=2$ brains, 3 coronal sections (10 area images)/brain. MRC1 and LYVE1 cell counts were from $n=3$ brains, 3 coronal sections ( 4 area images)/brain. The mean values for each set are depicted

(1:1000; Life Technologies, D3571) or Hoechst 33342 at 1:5000 (Fig. 1)was applied for nuclear labelling.

For adult cryosections of WT and A $\beta$ infused brains (Figs. 1, 6) $30 \mu \mathrm{m}$ brain cryosections were washed in phosphate buffered saline ( $\mathrm{pH}$ 7.4) and blocked in blocking buffer (0.3\% Triton $\mathrm{X}-100$ PBS $+5 \%$ donkey serum and $2.5 \%$ bovine serum albumin) overnight at $4{ }^{\circ} \mathrm{C}$. Sections were incubated in primary antibodies overnight at $4{ }^{\circ} \mathrm{C}$. After washing slides in PBS ( $\mathrm{pH} 7.4$ ), sections were incubated in secondary antibody for $4 \mathrm{~h}$ at room temperature. Sections were washed in PBS ( $\mathrm{pH} \mathrm{7.4),} \mathrm{stained} \mathrm{with} \mathrm{Hoecht}$ 33342 (1:5000) for $10 \mathrm{~min}$ and mounted in mowiol 4-88 (Sigma).

The sections were imaged with a Zeiss Airyscan 880 LSCM using a $63 \times$ oil immersion objective or Leica SP8 LSCM using $25 \times$ water and $63 \times$ oil immersion objectives.

IHC on embryonic mouse samples (Figs. 3, 4 and Supplementary Fig. 4) Pregnant mothers at 12.5, 13.5, and 18 days of gestation were euthanized by cervical dislocation, and embryos were immediately removed from the uterus and transferred to $1 \times 0.1 \%$ phosphate buffered saline on ice. Whole embryonic heads were fixed in $4 \%$ paraformaldehyde, made up in PB for $2 \mathrm{~h}$ on ice, rinsed $3 \times 15 \mathrm{~min}$ in $1 \times$ PBS at RT and then cryoprotected in $30 \%$ sucrose in PBS overnight at $4{ }^{\circ} \mathrm{C}$ on a shaker. Whole heads were embedded and frozen in either OCT (Tissue Tek; Fig. 3) or pre-cooled isopentane (2-methylbutane, Sigma-Aldrich; Fig. 4) on dry ice and stored at $-80^{\circ} \mathrm{C}$. $30 \mu \mathrm{m}$ coronal sections were cut on a Leica CM1850 cryostat onto glass slides, allowed to dry for an hour at RT and then stored at $-80{ }^{\circ} \mathrm{C}$.
Slides with sections were thawed to RT for $20 \mathrm{~min}$ and rehydrated via $3 \times \mathrm{PB}$ washes which were applied to sections to remove excess sucrose. Sections were then blocked in $1 \mathrm{~mL}$ of block solution consisting of $3 \%$ donkey serum (D9663-10ML Sigma), 0.3\% Triton X-100 in PB for an hour. Primary antibodies were added into $1 \mathrm{~mL}$ tris buffered saline/Tween 20 (TBST: comprised of $50 \mathrm{mM}$ Tris, $50 \mathrm{mM} \mathrm{NaCl}, 0.1 \%$ Tween 20) overnight at room temperature. The primary antibody solution was removed, the sample was washed $3 \times 10 \mathrm{~min}$ in $\mathrm{PB}$, and secondary antibody solution (all at 1:200 concentration) TBST was added for $2 \mathrm{~h}$ in the dark at room temperature. Secondary solution was then removed and washed $3 \times 10 \mathrm{~min}$ in PB. Sections were then mounted onto gelatin-coated slides in $\mathrm{PB}$, removing excess liquid and subsequently cover-slipped with mounting media (Citifluor, UK) and stored at $4{ }^{\circ} \mathrm{C}$ until imaging with a Zeiss Airyscan 880 LSCM using a $63 \times$ oil immersion objective and a Leica SP8 LSCM using $25 \times$ water and $63 \times$ oil immersion objectives.

IHC on mouse paraffin-embedded sections (Supplemental Fig. 1a, c) 6 month-old mouse brains in an AKR background were sectioned and paraffin-embedded [21]. Sections on slides were deparaffinised in xylene and rehydrated using graded alcohols. Immunohistochemistry for all antibodies required pre-treatment with a pressure cooker for $10 \mathrm{~min}$ in citrate buffer $\mathrm{pH}$ 6.0. Endogenous peroxidase activity was blocked in $0.3 \% \mathrm{H}_{2} \mathrm{O}_{2}$ in methanol for $10 \mathrm{~min}$ and non-specific binding with $10 \%$ dried milk solution. For this specific experiment, tissue sections were incubated with primary antibodies against human proteins that cross-react with mouse; PROX-1 (1:400; Acris), or VEGFR3 (1:40; R\&D Systems) for $1 \mathrm{~h}$ at RT, followed by biotinylated antirabbit IgG (1:200; Dako) or biotinylated anti-mouse IgG (1:200; Dako) for $30 \mathrm{~min}$ at RT and Avidin-Biotin complex (30 min; Dako). Colour was developed with di-aminobenzidine $/ \mathrm{H}_{2} \mathrm{O}_{2}$ [32].

Images were acquired using a Nikon Eclipse Ni microscope using $10 \times, 20 \times$, and $40 \times$ air objectives and $60 \times$ oil objective.

\section{Human brain immunohistochemistry}

\section{Cases}

Brain tissue from four normal controls was obtained through the brain donation program at Queen Square Brain Bank for Neurological Disorders (QSBB), Department of Clinical and Movement Neuroscience, UCL Queen Square Institute of Neurology. The demographic data for all cases are shown in Table 1. Ethical approval for the study was obtained from the Local Research Ethics Committee of the National Hospital for Neurology and Neurosurgery. 
Table 1 Human case data

\begin{tabular}{llllllllll}
\hline Case & QSBB number & Gender & Age at death & $\begin{array}{l}\text { PM delay } \\
\text { (hrs:mins) }\end{array}$ & Brain weight (g) & Thal phase & $\begin{array}{c}\text { Braak and } \\
\text { Braak stage }\end{array}$ & CERAD & ABC score \\
\hline 1 & P80-17 & M & 88 & $27: 30$ & 1330 & 3 & 4 & 2 & A2B2C2 \\
2 & P24-18 & F & 92 & $32: 30$ & 1450 & 3 & 3 & 2 & A2B1C1 \\
3 & P33-18 & M & 89 & $47: 05$ & 1356 & 0 & 0 & 1 & 0 \\
4 & P53/06 & M & 34 & $14: 00$ & n/a & 0 & 0 & A2B1C1 \\
5 & P17/07 & M & 38 & $80: 35$ & 1581 & 0 & 0 & A0B0C0 \\
6 & P78/06 & F & 68 & $45: 05$ & 1330 & & A0B0C0 \\
\hline
\end{tabular}

\section{Sample preparation and IHC}

Formalin-fixed, paraffin-embedded tissue Sections $(8 \mu \mathrm{m})$ from the frontal and occipital cortices were cut from cases 1-6 listed in Table 1. Sections were deparaffinised in xylene and rehydrated using graded alcohols. Immunohistochemistry for all antibodies required pre-treatment with a pressure cooker for $10 \mathrm{~min}$ in citrate buffer $\mathrm{pH}$ 6.0. Endogenous peroxidase activity was blocked in $0.3 \% \mathrm{H}_{2} \mathrm{O}_{2}$ in methanol for 10 min and non-specific binding with $10 \%$ dried milk solution. Tissue sections were incubated with primary antibodies; MRC1 (1:1000; R\&D systems), PROX1 (1:400; Acris), LYVE1 (1:50; Abcam), LYVE1(1:200; R\&D Systems), PDPN (1:350; Sigma-Aldrich), and VEGFR3 (1:40; R\&D Systems) for $1 \mathrm{~h}$ at RT, followed by biotinylated anti-rabbit $\operatorname{IgG}$ (1:200; Dako) or biotinylated anti-mouse $\operatorname{IgG}(1: 200$; Dako) for $30 \mathrm{~min}$ at RT and Avidin-Biotin complex (30 min; Dako). Colour was developed with di-aminobenzidine $/ \mathrm{H}_{2} \mathrm{O}_{2}$ [32].

Images were acquired using a Nikon Eclipse Ni microscope using $10 \times, 20 \times$, and $40 \times$ air objectives and $60 \times$ oil objective.

\section{Triple immunofluorescence}

Formalin-fixed paraffin-embedded tissue was sectioned at $8 \mu \mathrm{m}$ and $20 \mu \mathrm{m}$. Sections were deparaffinized in xylene and rehydrated using a gradient of alcohol. Endogenous peroxidases were first quenched with $0.3 \% \mathrm{H}_{2} \mathrm{O}_{2}$ in methanol for $10 \mathrm{~min}$. Antigen retrieval was undertaken in a pressure cooker for $10 \mathrm{~min}$ at maximum pressure in $10 \mathrm{mM}$ citrate buffer ( $\mathrm{pH}$ 6.0) and sections were blocked in $10 \%$ non-fat milk for $30 \mathrm{~min}$. Due to differing species combinations the following combinations of primary antibodies were used to assess colocalization; LYVE1 (Rabbit)/MRC1 (Mouse)/VEGFR3 (Goat); LYVE1(Goat)/MRC1(Mouse)/ PROX1(Rabbit); VEGFR3 (Goat)/PROX1(Rabbit)/ MRC1(Mouse). After washing, sections were sequentially incubated in AlexaFluor goat anti-rabbit 635, AlexaFluor goat anti-mouse 568 and AlexaFluor donkey anti-goat 488 at $1: 1000$ for $1 \mathrm{~h}$ at room temperature.

\section{Image processing and statistical analysis}

Post-image processing using raw data, including image thresholding and maximum intensity $z$-stack projections (adjusted for printing), were performed using ImageJ 7.7.2 software. Iso surface rendered images were processed via Imaris 8.4.1 (Bitplane A.G.). Images and figures were assembled using Adobe Photoshop and Adobe Illustrator. Statistical analysis and graphs were prepared using Microsoft Excel, GraphPad PRISM version 7.05 and the R bootstrap library using Q3.R. Bootstrapping was run without an assumption of normality, with $100 \mathrm{k}$ iterations and $\alpha=0.05$.

\section{Results}

\section{BLECs are present within the mouse leptomeninges}

In zebrafish, BLECs are unambiguously identified as vegfr 3 expressing cells that are in close association with meningeal blood vessels (Fig. 1a, b). Immunohistochemistry (IHC) on the cortical leptomeninges from a 17-week-old Tie2-GFP;NG2-DsRed double reporter mouse [25] using antibodies against mouse VEGFR3 also labelled cells that resided in close proximity to Tyrosine Protein Kinase Receptor 2 (Tie-2)-positive blood vessels (Fig. 1c, d). As in zebrafish, these cells did not associate with vessels that had penetrated into the brain. These cells did not correspond to Neural/Glial Antigen 2 (NG2)-positive pericytes or smooth muscle cells. Similar results were obtained with alternative VEGFR3 antibodies on paraffin-embedded tissue (Supplementary Fig. 1a, b) as well as by in situ hybridization against Vegfr3 mRNA (Supplementary Fig. 1d, e), ruling out antibody staining artefacts. To confirm the identity of these VEGFR3-positive cells as the mammalian BLEC homologue, we also examined mouse leptomeninges for the co-expression of VEGFR3, MRC1, and LYVE1, which are BLEC-associated markers in zebrafish. Although leptomeningeal cells expressed a heterogeneous combination of markers, numerous cells co-expressed all three tested BLEC markers (Fig. 1e-e"'). Cell counts from independent 
brains found that VEGFR3 co-localized with LYVE1 95\% (93-97\%, $n=2$ brains) of the time, while MRC1 co-localized with LYVE1 72\% (70-77\%, $n=3$ ) of the time (Fig. 1f, g). Because MRC1 and LYVE1 are expressed in subsets of macrophages and dendritic cells, and VEGFR3 has been reported in peripheral, but not meningeal, macrophages [30, 71] we examined the leptomeninges for expression of the additional lymphatic endothelial marker, PROX1, which along with VEGFR3 has not been described in CNS border macrophages [18, 29]. IHC on paraffin-embedded sections with antibodies against PROX1 labelled leptomeningeal cells (Supplementary Fig. 1c). Double in situ hybridization confirmed that these Proxl-positive cells also expressed Vegfr 3 mRNA (Supplementary Fig. 1f, h). Finally, we tried antibodies against the widely-used LEC marker, PODOPLANIN (PDPN), but, similar to a previous report [61], found in mouse tissue a nearly ubiquitous expression in the pia that extended into the glia limitans (Supplementary Fig. 2). Thus, the use of PDPN to identify individual cells in the meninges was not possible.

These data demonstrate that mouse leptomeninges contain a cell type that co-expresses at least three and likely four zebrafish BLEC markers that have not been described as co-expressed in other known leptomeningeal cell types. However, Mato/Fluorescent Granule Perithelial (FGP) cells, a phagocytic cell type of the mammalian meninges with auto-fluorescent inclusions, have been proposed to be the mammalian equivalent of BLECs [66]. We therefore tested whether zebrafish and mammalian BLECs auto-fluoresced under an epifluorescence microscope as was applied by Mato and colleagues [42] as well as by Venero Galanternik and colleagues [66]. No auto-fluorescent inclusions were detected with standard GFP, RFP and UV band passes. We also applied a 500-588 $\mathrm{nm}$ bandpass with high-intensity laser exposure under confocal microscopy. We detected auto-fluorescence from the blood vasculature but failed to observe auto-fluorescent inclusions in the meninges of either zebrafish (Supplementary Fig. 3) or mouse (Supplementary Video 1), suggesting that auto-fluorescence is not a consistent feature of this cell type.

Based on their expression profile similarity to zebrafish BLECs, we named these mammalian cells Leptomeningeal Lymphatic Endothelial Cells (LLECs) and sought to further characterize whether this cell type shared other features of BLECs.

\section{Ultrastructural properties of BLEC/LLECs are conserved in mice}

As previously described $[11,36]$, transmission electron microscopy (TEM) of zebrafish meninges identified cells outside of blood vessel basal laminae that possessed distinctively large, homogenous, electron-dense spherical inclusions (Fig. 2a). TEM of adult mouse cortical leptomeninges also identified cells with large, homogenous spherical inclusions (Fig. 2b). Although we cannot rule out their existence, we have not been able to identify other cell types containing such large, homogenous inclusions. To confirm unambiguously that these cells corresponded to BLECs, we first performed immunogold EM for YFP on the meninges of zebrafish carrying a transgenic BLEC reporter $[\mathrm{Tg}$ (flt4:mCitrine)] and found the cells with large, round inclusions were labelled (Fig. 2c, asterisks). In mouse leptomeninges, immunogold EM with antibodies against LYVE1 labelled cells containing large, homogeneous inclusions that are features of BLECs (Fig. 2d, asterisks). LYVE1 is also expressed in meningeal macrophages, and immunogold EM additionally labelled an ultrastructurally distinct population of rounded cells that possess numerous, irregularly shaped, heterogenous inclusions (Fig. 2f, g) that are characteristic of macrophages. Consistent with this interpretation, a similar macrophage-like cell type was observed in the meninges of $\operatorname{Tg}($ ftt4:mcitrine $)$ zebrafish, but these cells were never labelled by immuno-EM against YFP, indicating that these cells lack canonical BLEC marker expression. Together, these results show that the ultrastructural distinctiveness of zebrafish BLECs is conserved in mouse LLECs and that these cells are a distinct population from CNS macrophages in both species.

\section{Development of murine LLECs is distinct from cells of myeloid origin}

To further explore whether mouse LLECs are distinct from border macrophages, we investigated the developmental origins of these cells. In zebrafish and mice, meningeal macrophages are derived from a monocytic lineage and therefore require the transcription factor PU.1 to differentiate [2, $18,43]$. In contrast, zebrafish BLEC development does not require pU.1, consistent with their distinct ontological origin that is more similar to peripheral lymphatic vessels [36, 66]. We therefore examined whether cells that express LLEC markers were still present in the meninges of PU.1 knockout mice, which lack all macrophages [43].

Because PU.1 knockout mice are perinatal lethal, we first confirmed the presence of LLECs in the developing meninges (E12.5-E18.5) using IHC against LYVE1, PROX1, and $\mathrm{MRC} 1$ and found cells expressing these three markers as early as E12.5 (Fig. 3a-1). Similarly, in PU.1 knockout mice, which lack macrophages and other differentiated myeloid cells $[18,43]$, cells were still detected that co-expressed at least three BLEC markers (Fig. 4e-h), although MRC1 expression appeared reduced compared to wild-type controls (Fig. 4c, g). We confirmed these PU.1-independent cells were expressed in the developing meninges by double labelling these cells with antibodies to LYVE1 and LAMININ, 


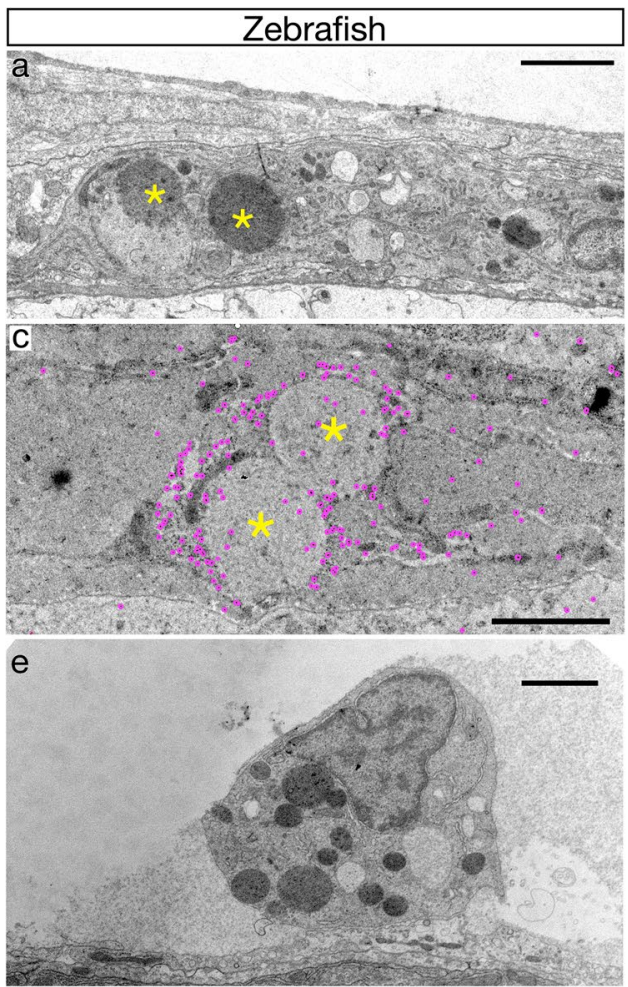

Fig. 2 Ultrastructural properties of BLECs/LLECs are conserved in zebrafish and mice. a Representative TEM micrograph of adult zebrafish meninges. The large, round, densely and homogenouslystained inclusions (yellow asterisks) of a putative BLEC are indicated. Scale bar $=2.5 \mu \mathrm{m}$ (in all images). $n=2$ brains. b Representative TEM micrograph of adult mouse leptomeninges. Putative LLECs have their large inclusions marked with yellow asterisks. $n=2$ brains. c Cells with large inclusions (yellow asterisks) characteristic of BLECs are immunologically labelled with post-embed detection of GFP in $\operatorname{Tg}(f t 4: g f p)$ adult brains using a $20 \mathrm{~nm}$ gold-labelled secondary. Minimal contrast staining was used to prevent obscuring of the nanogold particles (highlighted in magenta). $n=2$ brains. d

which delineates the meninges from the parenchymal surface and surrounding tissue (Supplementary Fig. 4a, c) [10]. We conclude that murine LLEC development is not dependent on the PU.1 transcription factor, which is similar to zebrafish BLECs and unlike neighbouring macrophages $[36,66]$.

\section{Zebrafish BLECs and mouse LLECs endocytose $A \beta$ 1-40 more efficiently than macrophages}

Zebrafish BLECs have the ability to internalize macromolecules up to $500 \mathrm{kD}$ in size [36]. However, since not all molecules below this size limit (e.g., Evan's Blue, molecular weight, $961 \mathrm{Da}$ ) can be internalized by zebrafish BLECs, we decided to examine whether disease-relevant molecules such as Amyloid $\beta 1-40$ (A $\beta$; molecular weight, $5 \mathrm{kD})$ can also be endocytosed by BLECs. We specifically chose $A \beta 1-40$ over $A \beta 1-42$ because $A \beta 1-40$ is a major contributor to cerebral amyloid angiopathy (CAA, [60])

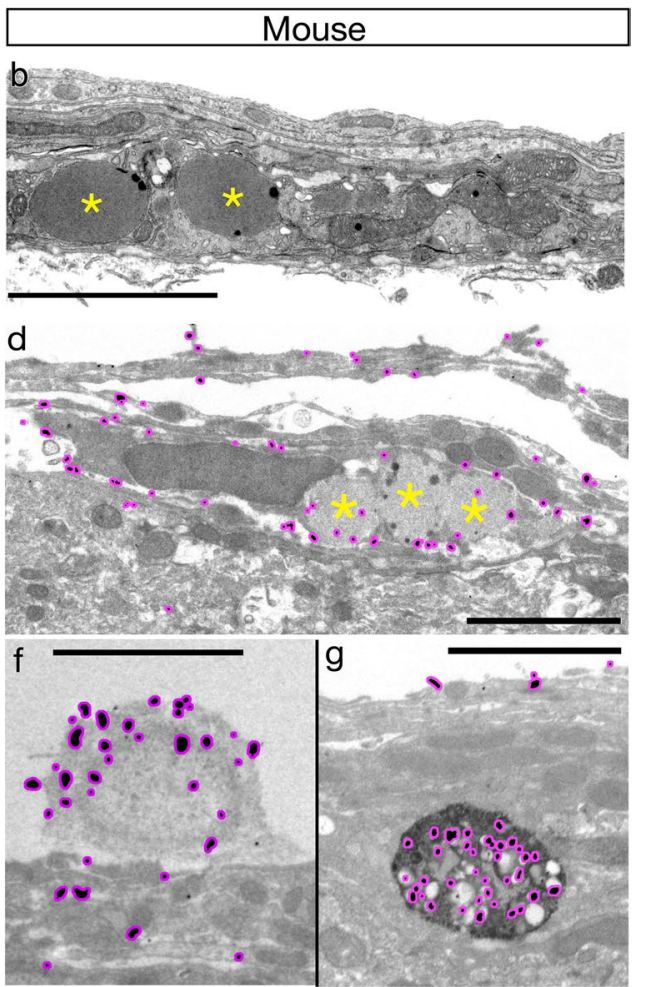

Mouse meningeal cells with large inclusions (yellow asterisks) are labelled by pre-embed detection of LYVE1 using a nanogold secondary with silver-enhancement. The silver grains are highlighted with magenta. Note the LYVE1-positive cell has silver grains present near the outer membrane. $n=2$ brains. e An example of a GFP-negative cell in zebrafish $\operatorname{Tg}(f t 4: g f p)$ adult meninges with similar ultrastructural properties to macrophages. $n=2$ brains. f A second population of LYVE1-positive cells in the mouse leptomeninges contain multiple small, irregular, heterogeneous vesicles with silver grains (magenta) present within the cytoplasm and vesicles. These cells are ultrastructurally similar to macrophages (e). $n=2$ brains

and experimentally aggregates less readily, making experiments much easier to control. Fluorescently-tagged $A \beta$ was injected into a pocket of CSF dorsolateral to the posterior hindbrain ventricle of 7 days post fertilization (dpf) transgenic Tg(kdr-l:mCherry); Tg(flt4:mCitrine);casper zebrafish larvae, in which the vasculature is labelled with mCherry (red) and BLECs with mCitrine (green), and the subsequent distribution of $\mathrm{A} \beta$ was followed by live confocal imaging (Fig. 5a, c). After 30 min, A $\beta$ accumulated in flt4/vegfr3-positive BLECs but not in the $k d r$ $l$-positive vasculature (Fig. 5c, d; Supplementary Video $2)$. To observe whether meningeal macrophages also internalized $A \beta$, we injected $A \beta$ into a 7 dpf transgenic line, Tg (mpeg 1:Gal4-FF) $)^{g l 25} ; \mathrm{Tg}(U A S-E 1 b: n f s$. mCherry )$^{c 264} ; \mathrm{Tg}\left(\right.$ ftt4:mCitrine); nacre $^{-/}$, in which BLECs express mCitrine (green) and macrophages/microglia express mCherry (red). After 45 min, $A \beta$ again accumulated in BLECs, but no $A \beta$ was detectable in any of the nearby 

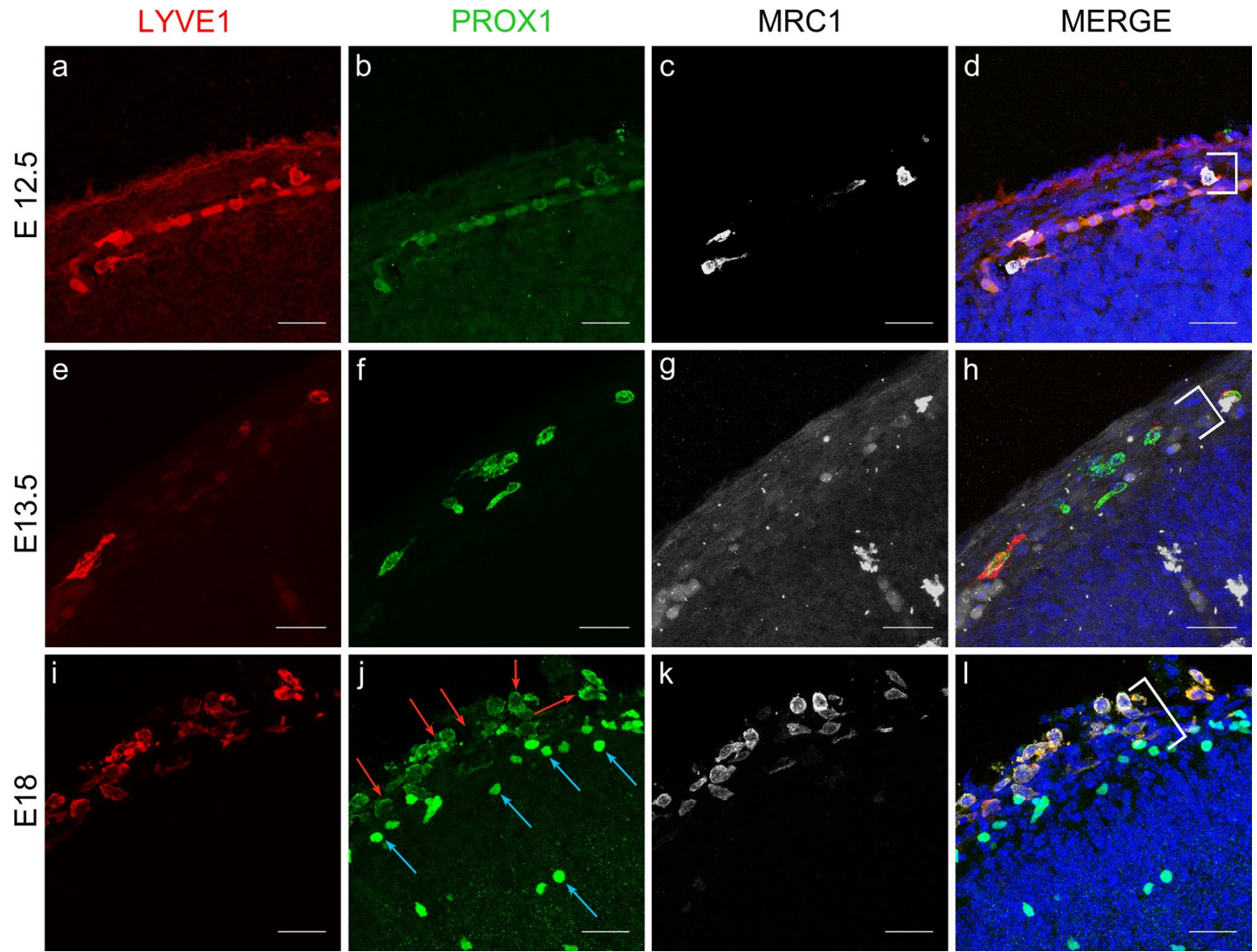

Fig. 3 Cells expressing LLEC markers are present within embryonic mouse leptomeninges. a-d As revealed by IHC, E12.5 mouse meninges (white bracket) contain cells that co-express LYVE1 (red), PROX1 (green), and MRC1 (white). DAPI marks the nuclei in blue (d). Scale $=30 \mu \mathrm{m} . n=3$ brains. e-h E13.5 mouse meninges (white bracket) contain cells that co-express LYVE1 (red), PROX1

mpeg1-positive macrophages (Fig. 5e, e'). We conclude that zebrafish BLECs outperform macrophages in the acute internalization of $A \beta$.

To test whether mouse LLECs internalize macromolecules, both $10 \mathrm{kD}$ cascade blue dextran and fluorescentlytagged $A \beta$ (HiLyte-647) were slowly co-infused $(1 \mu \mathrm{L} /$ minute) into the cisterna magna of 2 -month old mice (Fig. 6a, arrow) that were sacrificed after $60 \mathrm{~min}$ and processed for IHC. The $10 \mathrm{kD}$ dextran was detected within PROX1 and LYVE1 co-expressing cells (Supplementary Fig. 5), demonstrating that LLECs can internalize macromolecules. In addition to the walls of meningeal blood vessels (e.g. Fig. $6 \mathrm{f}^{\prime \prime}$ ), A $\beta$ was also internalized by cells that co-expressed pairwise combinations of the BLEC associated markers MRC1, LYVE1, VEGFR3, and PROX1 (Fig. 6d-f'"' and Supplementary Fig. 5). Although technical constraints precluded the simultaneous imaging of fluorescently-tagged $A \beta$ and three LLEC markers, the high rate of LLEC marker co-localization (often $>90 \%$ e.g. see (green), and MRC1 (white). DAPI marks the nuclei in blue (h). Scale $=30 \mu \mathrm{m} . n=3$ brains. i-l E18 mouse meninges (white bracket) contain cells that co-express LYVE1 (red), PROX1 (green), and MRC1 (white). PROX1 is cytoplasmic ( $\mathbf{j}$, red arrows) in the meninges but nuclear in neurons ( $\mathbf{j}$, blue arrows). DAPI marks the nuclei in blue (l). Scale $=30 \mu \mathrm{m} . n=3$ brains

Fig. 1 and Supplementary Fig. 1) in the leptomeninges means the uptake rates observed in these pairwise combinations is a strong indication that LLECs expressing at least four markers are internalizing $A \beta$.

Since $A \beta$ is preferentially internalized by BLECs and not by macrophages in zebrafish, we quantified the rates of $A \beta$ internalization by these populations. On average, 95\% of mouse LLECs, which express both VEGFR3 and LYVE1, had internalized $A \beta$ after 60 min (Fig. 6c). In contrast, $72 \%$ of MRC1, LYVE1 double positive cells, which identifies both putative BLECs and macrophages, internalized $A \beta$, a significantly lower rate compared to LLECs ( $p<0.05$, bootstrap). The rates of $\mathrm{A} \beta$ internalization were even lower for cells expressing only MRC1, with only $30 \%$ of these cells internalizing $A \beta$ (Fig. 6c). Together with the zebrafish data, these results suggest that a greater capacity to internalize $A \beta$ is a hallmark feature of BLECs and LLECs that functionally distinguishes them from meningeal macrophages. 

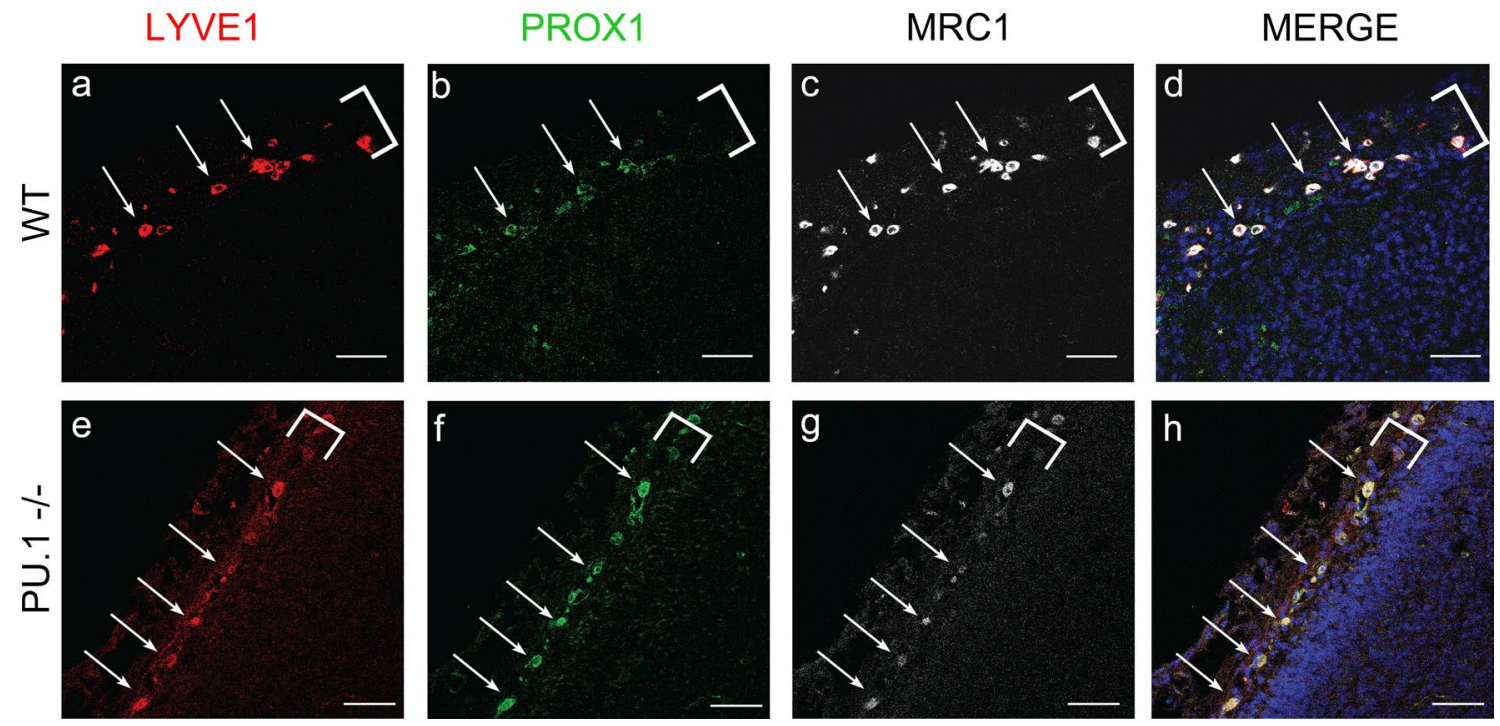

Fig. 4 Mouse LLECs develop independent of the transcription factor PU.1. a-d As detected by IHC, E15.5 wild-type mice have cells that co-express LYVE1 (a, red) PROX1 (b, green) and MRC1 (c, white) in the developing meninges (white bracket). DAPI labels nuclei blue in the merged image (d). White arrows indicate cells with these three

\section{BLEC/LLEC markers are co-expressed in cells of the human meninges}

To determine whether LLECs are also present in human meningeal tissue, we performed immunostaining with antibodies against LLEC proteins on sections from postmortem human brains that lacked obvious neuropathology (Table 1). As in zebrafish and in mice, VEGFR3, LYVE1 and MRC1 were all found to be expressed within a heterogeneous population of cells within the pia and subarachnoid space of the leptomeninges of these samples (Fig. $7 \mathrm{a}-\mathrm{c}$ ). We then examined post-mortem meninges obtained from elderly human samples (aged 88-92) showing various degrees of neuropathology (Table 1) and again found VEGFR3, LYVE1, and MRC1 expression (Fig. 7d-f, and Supplementary Fig. 6). VEGFR3 was also strongly expressed in the lining of leptomeningeal vascular walls (Supplementary Fig. 7e, black arrows), in a tight layer of interdigitated cells comprising the arachnoid barrier (Supplementary Fig. 7d, orange arrows) [63, 70], and in clusters of cells corresponding to the arachnoid trabeculae (Supplementary Fig. 7b), including cells with pale nuclei with small prominent nucleoli typical of leptomeningeal and meningioma cells (Supplementary Fig. 7c) [12, 62]. This helps to identify these cells as phenotypically leptomeningeal cells. These observations raise the possibility that human leptomeninges contain LLECs, although the expression of some markers such as markers. Scale $=50 \mu \mathrm{m} . n=2$ brains. e-h) The meninges (white bracket) of E15.5 PU.1 knockout siblings contain many cells (white arrows) that co-express LYVE1 (e, red), PROX1 (f, green), and $\operatorname{MRC1}(\mathrm{g}$, white). Scale $=50 \mu \mathrm{m} . n=3$ brains

VEGFR3 is more widespread in other meningeal tissue than observed in fish and rodents.

To determine if the cells in the pia and subarachnoid space that express lymphatic markers represent LLECs, we performed triple-labelling fluorescent IHC on post-mortem human brain tissue for MRC1, LYVE1, and VEGFR3. We found several examples of these three LLEC markers coexpressed in the same leptomeningeal cells (Fig. 7g-p and Supplementary Video 3). To emphasize the spatial locations of LLECs relative to vessels and each other and to more clearly make out their morphological features, we used the Imaris imaging software to make 3-D reconstructions from the serial confocal images of the leptomeningeal human post-mortem tissue (Supplemental Fig. 5e-h). Consistent with LLECs in zebrafish and mouse, a subset of triple-positive cells were closely associated with vessels within the leptomeningeal layer, while their cell bodies remained outside of the vascular basement membrane. Morphologically, these cells were similar to zebrafish and mouse BLECs, with long, thin processes near blood vessels. Several of these processes formed unusual looplike structures of unknown functional significance that were also a common morphological feature observed in zebrafish BLECs (Supplementary Fig. 8).

Taken together, the co-expression of three lymphatic markers in subarachnoid cells with a distinctive morphological character supports the existence of LLECs in human leptomeninges. 

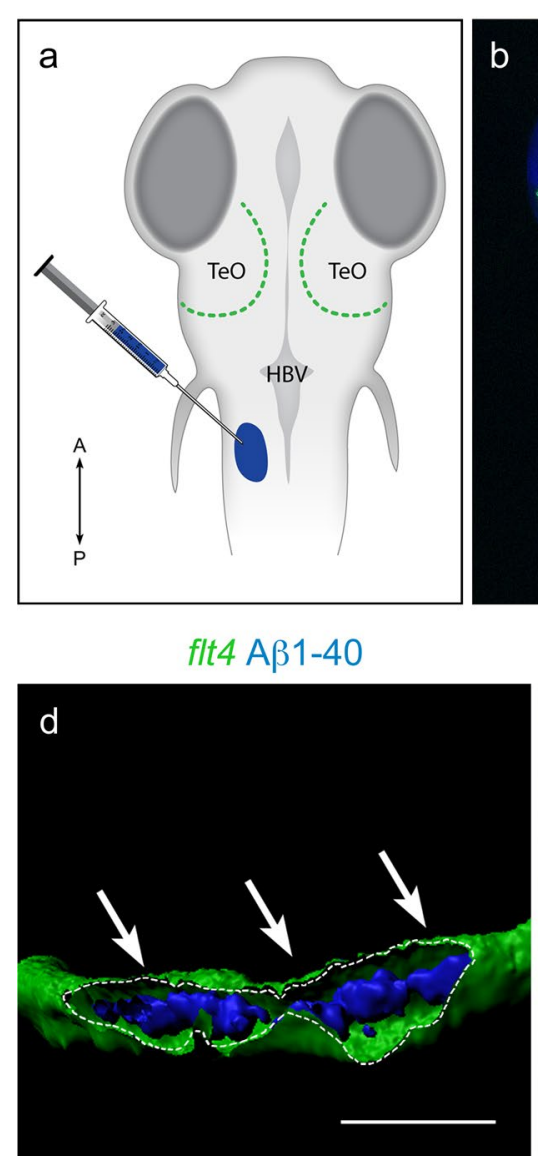

$k d r l$ flt4 $A \beta 1-40$

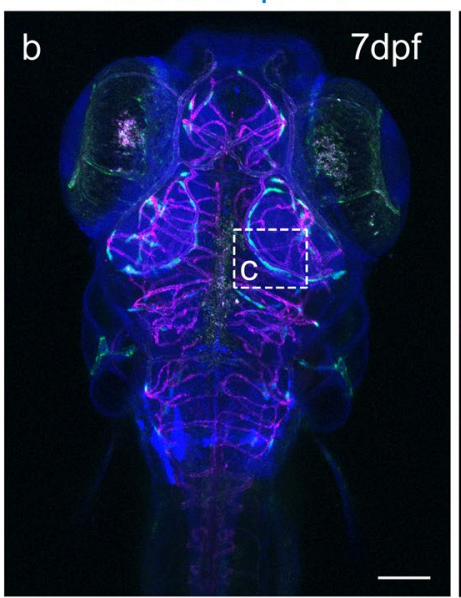

mpeg-1 flt4 A $\beta 1-40$

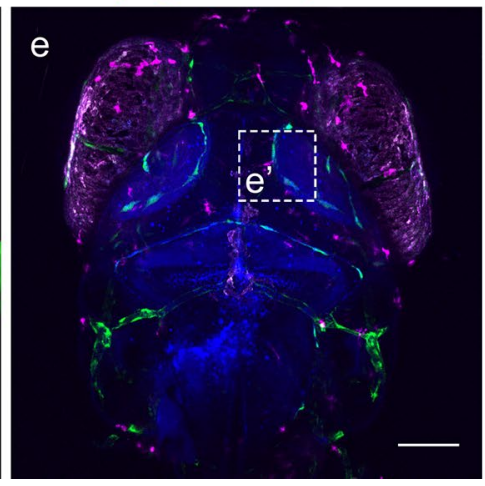

$k d r l$ flt4 $A \beta 1-40$

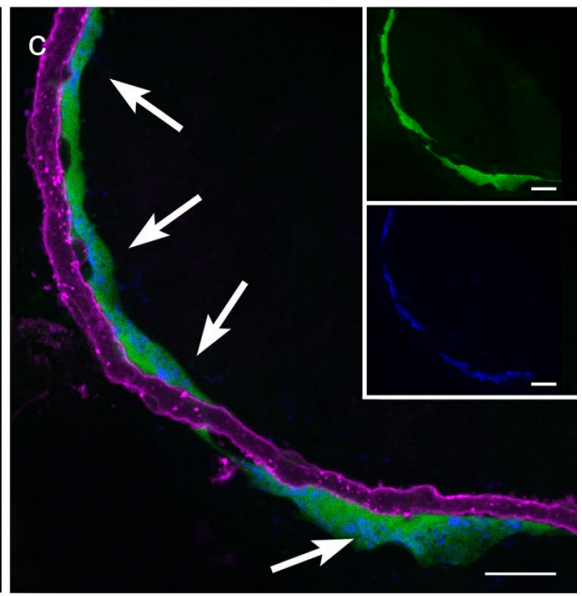

mpeg-1 flt4 A $\beta 1-40$

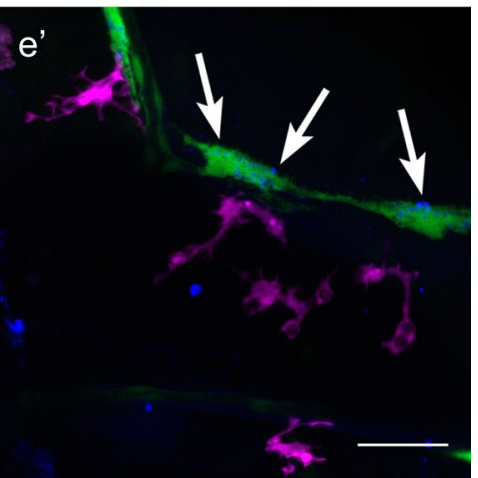

Fig. 5 Zebrafish BLECs, but not macrophages, take up A $\beta 1-40$. a Schematic showing the location of BLECs (green) relative to the A 1 1-40 injection site into a pocket of CSF near the hindbrain ventricle $(\mathrm{HBV}) . \mathrm{TeO}=$ Optic Tectum. $n=4$ brains $\mathbf{b}$ Confocal projection of double transgenic $\mathrm{Tg}(\mathrm{kdr}$-l:mCherry); Tg(flt4:mCitrine);casper 7dpf larvae, which labels vasculature in red and BLECs in green, injected with A $\beta 1-40$ (blue). Dotted box detailed in (c). Scale $=150 \mu \mathrm{m} . n=4$ brains c After injection, A $\beta 1-40$ (blue) accumulates within $m$ Citrinepositive BLECs (green, white arrows showing co-localization) but not within $m$ Cherry-positive vasculature (magenta). The green (BLECs) and blue (A $\beta 1-40)$ channels are shown separately in the insets.

\section{Discussion}

BLECs were originally described as a non-lumenized endocytic cell type of lymphatic developmental origin and molecular expression that resides in the zebrafish meninges $[11,36,66]$. Here, we described LLECs, cells with similar molecular, ultrastructural, developmental, and functional characteristics as BLECs in both mouse and human leptomeninges. The location and functional properties of LLECs indicate potential role(s) for these cells in the immunological organization of this meningeal compartment and in the regulation of CSF protein homeostasis.
Scale $=30 \mu \mathrm{m} . n=4$ brains. d A 3-D reconstruction of the mCitrine positive BLEC (green) shows a cutaway (dotted line) into the interior portion of the cell to highlight the internalization of $A \beta 1-40$ (blue with white arrows). Scale $=15 \mu \mathrm{m} . n=4$ brains. e A representative confocal projection of double transgenic Tg(mpeg1:mCherry); Tg(flt:mCitrine); nacre $^{-/-} 7 \mathrm{dpf}$ larvae, which labels macrophages in magenta and BLECs in green, injected with A $\beta 1-40$ (blue). The white dotted box is detailed in ( $\mathbf{e}^{\prime}$ ) showing A $\beta 1-40$ (blue) accumulates within $m$ Citrine-positive BLECs (green) but not within $m$ Cherry-positive macrophages (magenta). White arrows point to co-localization of green BLECs with blue A $\beta 1-40$. Scale $=30 \mu \mathrm{m} . n=3$ brains

\section{LLECs are distinct from other known cell types}

We provide evidence that zebrafish BLECs have an equivalent cell type in both mouse and humans that we have named LLECs. Do LLECs represent a unique cell type? Although cells expressing the lymphatic markers of BLECs have not to our knowledge been previously described in the leptomeninges, there are three other meningeal cells types that share at least a few LLEC features, including Mato Cells/FGPs, meningeal macrophages, and telocytes $[8,16,40]$. We consider whether LLECs are equivalent to, or a subpopulation of, each of these cell types in turn. 



Fig. 6 Mouse LLECs take up A $\beta$ 1-40. a Schematic showing the site of dye and A $\beta 1-40$ perfusion into the CSF via the cisterna magna (arrow) of a 2-month old mouse. The dotted line indicates the plane of section. $A$ anterior, $P$ posterior, $D$ dorsal, $V$ ventral. b Coronal brain section indicating the areas imaged. SF4 refers to area captured in Figure S4. $\mathbf{c}$ The percentage of each labelled cell type that internalized perfused $A \beta$. Cells co-expressing VEGFR3 and LYVE1 take up $\mathrm{A} \beta$ at a higher rate than MRC1, LYVE1 double-positive cells as well as MRC1-positive, LYVE1-negative cells $(p \leq 0.05$, bootstrap). VEGFR3, LYVE1 counts, $n=2$ brains (3 sections/brain).

\section{Mato cells/FGPs}

One of the initial characterizations of zebrafish BLECs suggested these were the fish homolog of Mato Cells/FGPs mainly based on the presence of large, auto-fluorescent

MRC1, LYVE1 counts, $n=3$ brains ( 3 sections/brain). d-d"' Cells of the adult mouse meninges that co-express VEGFR3 (d, green) and LYVE1 (d', white) internalize A $\beta 1-40$ (d", cyan). Scale $=20 \mu \mathrm{m}$. e-e $\left.\mathbf{e}^{\prime \prime \prime}\right)$ Cells of the adult mouse meninges that co-express VEGFR3 (e, green) and MRC1 ( $\mathbf{e}^{\prime}$, white) internalize A $1-40$ ( $\mathbf{e}^{\prime \prime}$, cyan). Scale $=40 \mu \mathrm{m}$. $\left.\mathbf{f}-\mathbf{f}^{\prime \prime \prime}\right)$ Cells of the adult mouse meninges that coexpress MRC1 (f, magenta) and LYVE1 (f' ${ }^{\prime}$, white) internalize A $\beta 1$ $40\left(\mathbf{f}^{\prime \prime}\right.$, cyan). The walls of a blood vessel (white arrowhead, $\left.\mathbf{f}^{\prime \prime}\right)$ also accumulate $A \beta 1-40$. Scale $=60 \mu \mathrm{m}$

inclusions [66]. However, we have been unable to identify auto-fluorescent inclusions in either zebrafish or mouse, suggesting that auto-fluorescence is not a consistent feature of BLECs, perhaps reflecting dietary differences affecting lipid content within such inclusions [42]. 

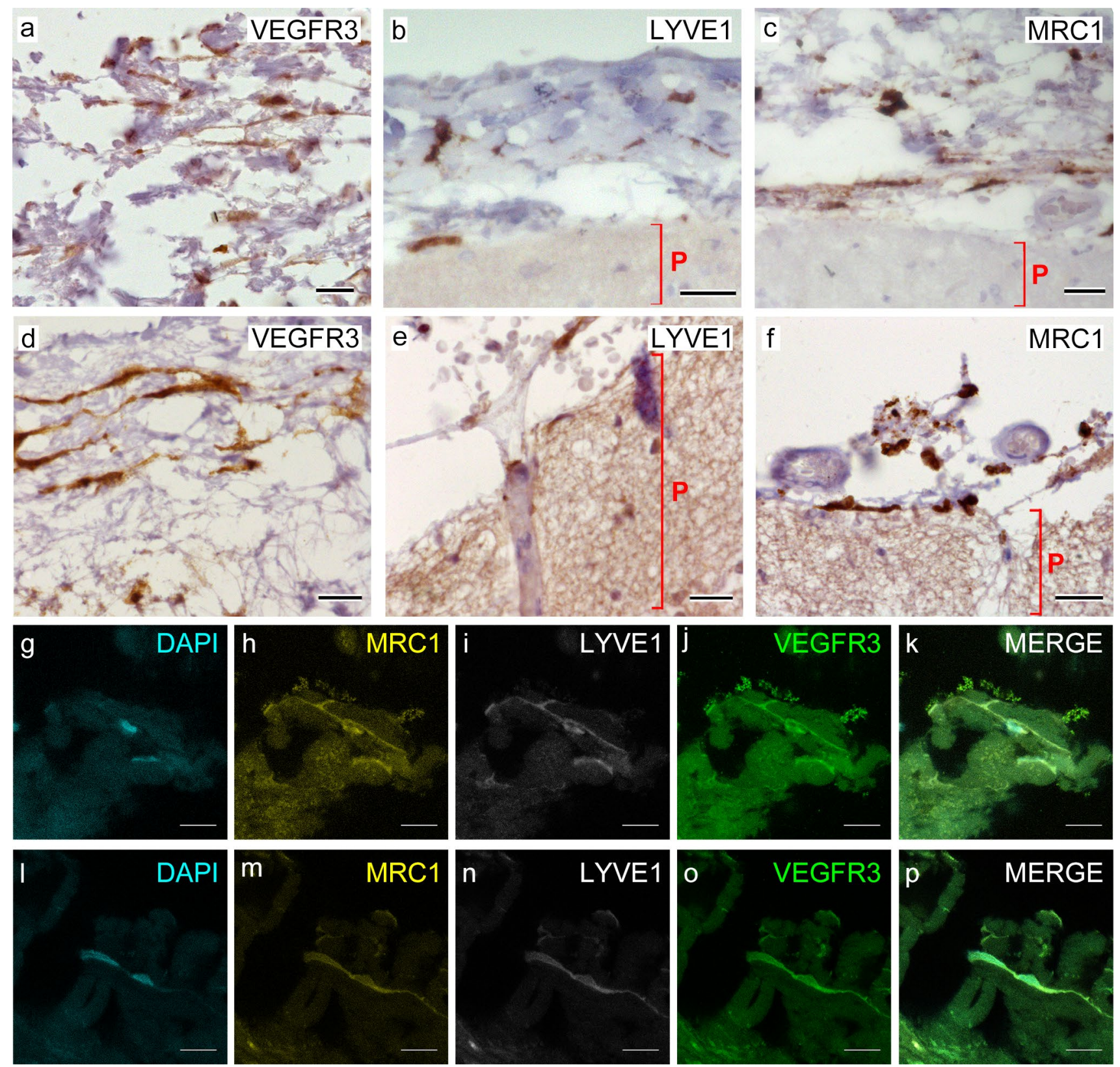

Fig. 7 Cells of human meninges co-express LLEC markers. a-c DAB-IHC with single antibodies detects VEGFR3 (a), LYVE1 (b), and MRC1 (c) in the meninges of human post mortem brain showing no signs of neuropathology. These images are taken from a 38 year old male (sample P17/07, Table 1), and confirmed in $\mathrm{n}=2$ additional samples. $P$ parenchyma. Scale $=150 \mu \mathrm{m}(\mathbf{a}) ; 40 \mu \mathrm{m}(\mathbf{b})$; and $20 \mu \mathrm{m}$ (c). d-f DAB-IHC with single antibodies detects VEGFR3 (b),

Additionally, ultrastructural analysis of Mato Cells/FGPs has described the inclusions as more heterogeneous in size and shape, with many taking on a foamy appearance. In contrast, immuno-EM labelled BLECs in both fish and LLECs in mice contain mostly large, round, uniformly electron-dense inclusions (Fig. 2b), with some neighbouring cells more closely resembling FGPs (Fig. 2e-g).
LYVE1 (c), and MRC1 (d) in elderly human meninges (age: 89-92) with evidence of neuropathology and confirmed in $n=3$ brains (Table 1). P, parenchyma. Scale $=20 \mu \mathrm{m}$. g-p IHC with fluorescent antibodies detects human meningeal cells that co-express MRC1 (h, $\mathbf{m}$, yellow), LYVE1 (i, n, white), and VEGFR3 (j, o, green). Nuclei/ RNA are labelled with DAPI $(\mathbf{g}, \mathbf{l}$, blue) and images are merged in ( $\mathbf{k}$, p). Scale $=10 \mu \mathrm{m}$

Finally, FGPs are described as positioned between the smooth muscle cells and the glia limitans [42], whereas BLECs in zebrafish and LLECs in mice remain external to vascular basement membranes (Fig. 2a, b) [36]. Although we cannot rule out the possibility that LLECs are a subpopulation of Mato Cells/FGPs, perhaps one that has dynamically changed in response to unknown cues, our 
data indicate that Mato Cells and LLECs are distinct cell types in the vertebrate meninges.

\section{Meningeal macrophages (mMФs)}

While LLECs and mMФs express some of the same genes, including MRC1, the lymphatic and LLEC markers PROX1 and VEGFR3 have not previously been described in mMФs (Fig. 1, 7, Supplementary Fig. 1\&5). Thus, although they share some morphological and phagocytic characteristics, LLECs and $\mathrm{mM} \varphi$ s likely play non-overlapping roles in meningeal surveillance and maintenance. Consistent with this, in both zebrafish and mouse, BLECs/ LLECs more efficiently internalized $A \beta$ than neighboring mMФs (Fig. 5, 6, Supplementary Fig. 5).

We also found that LLECs and $\mathrm{mM} \varphi s$ do not share a developmental origin. In zebrafish, both lineage tracing and mutagenesis of signalling genes involved in the specification of lymphatic endothelium established a lymphatic origin for BLECs [11, 36, 66]. Zebrafish BLECs also developed normally in the absence of the pU.1 transcription factor, which is essential for the development of mpeg 1-positive macrophages. In mice, $\mathrm{MRC}^{+} \mathrm{mM} \Phi \mathrm{s}$ are derived from the yolk sac or liver in a PU.1-dependent manner and begin colonizing the leptomeninges from E9.5 [18]. In contrast to $\mathrm{mM} \Phi \mathrm{s}$ but similar to zebrafish BLECs, we detected LYVE1, MRC1, and PROX1 triple-positive cells at E15.5 in PU.1 knock-out mice (Fig. 4), demonstrating that mouse LLECs develop independent of this essential $\mathrm{mM} \Phi$ s transcription factor.

Together, the molecular, developmental, and functional data indicate that LLECs and $\mathrm{mM \Phi s}$ are distinct classes of meningeal cells.

\section{Telocytes}

Telocytes are a recently discovered stromal interstitial cell type found in many organs including the heart [48, 52], intestines [64] and uterus [47]. Telocytes are characterized by their small cell bodies, unusually long and fine processes, and their close association with vasculature. Telocytes are often mistaken as other stromal cell types such as fibroblasts, especially in the meninges and choroid plexus $[9,46]$. However, telocytes are not noted for large intracellular inclusions, phagocytic/endocytic properties, or expression of lymphatic-associated markers as seen in LLECs $[8,16]$. In addition, the processes of LLECs are not as long and fine as in telocytes, which can be hundreds of $\mu \mathrm{m}$ long [15] and as thin as $0.2 \mu \mathrm{m}$ [65]. LLECs and telocytes are therefore likely to be distinct classes of cells.

\section{Potential roles for BLECs in the surveillance and clearance of CSF solutes}

The ability of BLECs to readily endocytose macromolecules up to $500 \mathrm{kD}$ in an Mrc1-dependent manner [36] and for mammalian LLECs to internalize dyes of at least $10 \mathrm{kD}$ suggests that they participate in the surveillance and clearance of CSF solutes. Mrc1 is a pattern recognition receptor that is involved in the identification, binding, and endocytosis of pathogens, including bacteria involved in tuberculosis (Mycobacterium tuberculosis) and meningitis (Streptococcus pneumoniae) and fungi such as Candida albicans [6, 17, 49, 54, 56, 57]. In other cellular contexts, MRC1 can be exploited by pathogens. For example, viruses such as Influenza type A can enter and infect MФs via MRC1 [50], and Mycobacterium tuberculosis can co-opt lymphatic endothelial cells in lymph nodes to serve as a replicative niche following MRC-dependent endocytosis [35]. Whether LLECs also participate in the uptake of pathogens or can serve as a reservoir for infection remains to be determined. MRC1 also participates in immune organization, for example by trafficking lymphocytes along lymphatic endothelium to draining lymph nodes, a process also exploited by tumours to metastasize to nodes [41]. Whether the densely interconnected network of LLECs that reside in the meninges perform a similar immune organizational function, for example by providing signalling cues or sites of attachment for lymphocytes [53], is an interesting question for future investigation.

While BLECs and LLECs can internalize a diversity of macromolecules, the selective ability of BLECs/LLECs to internalize $A \beta$ more readily than meningeal macrophages suggests that these cells may especially participate in the clearance of $\mathrm{A} \beta$, which accumulates within the wall of leptomeningeal arteries in CAA [68]. Because CAA may commence with $A \beta$ accumulation in leptomeningeal vessels during aging as well as in Alzheimer's Disease patients [19, 55], and cases of CAA solely within the leptomeninges have been reported [58], LLECs are well positioned to participate in the progression of this disease. Interestingly, chemical ablation of MRC1-expressing perivascular macrophages (pvM $\varphi$ ) using mannosylated clodronate containing liposomes exacerbates the development of CAA in a mouse model [20]. Since MRC1-expressing LLECs would likely also be eliminated by this methodology, this result should be revisited to examine whether LLECs participate in playing a protective role against $A \beta$-related disease. If so, whether LLECs have been lost or have diminished function in patients with CAA should also be examined.

More generally, the discovery of LLECs expands the diversity of "brain" lymphatics beyond the lymphatic vessels of the dura mater to also include cells within the leptomeninges. Although the role of dural brain lymphatics in the clearance of the brain and CSF remains controversial, there 
are several possibilities by which LLECs may interact with dural lymphatics to participate in the drainage and macromolecular clearance of the CSF that warrant further exploration. First, although under normal conditions the LLECs are not lumenized like the dural lymphatics, zebrafish BLECs can transiently form tubes that penetrate the brain parenchyma upon brain vascular injury [13]. Whether mammalian LLECs can also form tubes in certain disease or injury contexts to directly participate in lymphatic drainage of the brain should be examined in future studies. Second, the loosely interconnected meshwork of BLECs/LLECs could physically interact with dural lymphatics to participate in solute removal. For example, fluorescent tracer imaging experiments have revealed lymphatic articulations from the dura into the subarachnoid space near tracer "hot spots" at several points along the skull [37], and a recent paper has characterized a set of dural lymphatic vessels in the base of the mouse skull that have valves and other structures of classical lymphatics, lie close to the subarachnoid space, and reside in a thinner part of the dura mater [1]. Whether the distribution of LLECs within the leptomeninges shows a similar intracranial variation is unknown, but holocranohistochemistry to preserve anatomical architecture [60] could facilitate mapping the positions of LLECs relative to dural lymphatic articulations and other important structures of the meninges.

The ability of LLECs to participate CSF macromolecular clearance (at least under experimental conditions) also makes them potentially interesting targets for clinical applications. For example, enhancing dural lymphatic development using soluble VEGF improved macromolecule drainage and cognitive impairment in an AD mouse model [44]. How the VEGFR3-expressing LLECs respond to VEGF signalling is not known, but LLECs may also have been affected alongside the dural lymphatics when manipulated with VEGFR signalling [1,44]. Whether LLEC number or endocytic function can be enhanced, and whether this has a protective effect in animal models of CAA, AD, or other pathological states would not only demonstrate a critical role for LLECs in disease progression but would also highlight LLECs as a promising target for therapeutic intervention.

Acknowledgements This work was supported by an Alzheimer's Research UK senior fellowship (TL), an Excellence Fellowship (JR), ERC Starting Grant (JR) [\#282027], an ARUK Interdisciplinary Award (JR), a BBSRC grant (JR and TH) [\#BB/T001844/1], a Welcome Investigator Award to CR [205099/Z16/Z], and grants from the National Institutes of Health (JJI, AG054456, NS089709; JRG, AG060681). A P30 grant (NS061800; Aicher PI) supported confocal microscopy conducted at OHSU. We would like to thank Francis Edwards, Damian Cummings, Dervis Saleh, John Parnavelas, Steve Hunt, Liz Milward and Ritambhara Aryal for mouse tissue. We also would like to thank Mark Turmaine for assistance with EM, Oakley Morgan and Rhys Burrows for cryosection training, Chris Thrasivoulou and Tim Robson for confocal imaging expertise, members of the UCL Fish Facility for animal husbandry, Laura Denti for mouse breeding, Jane Pendijiky for work with figures and art, Declan Lyons and Benjamin M. Davis for assistance with data analysis, Rebecca Thorne for repeating cell counts, and Anita Impagliazzo for her art. We also acknowledge Stefanie Kaech-Petrie and Crystal Chaw at the OHSU Advanced Light Microscopy Core for their technical expertise.

Author contribution SSG, JR, and TH conceived of the experiments with input from JI, CR, and TL. SSG directly supervised or performed all experiments and data analysis, along with JG (mouse perfusions); $\mathrm{CT}$ and AF (zebrafish injections and molecular biology); $\mathrm{MB}, \mathrm{RCa}$, and RCo (mouse work); AG (microscopy); TH (electron microscopy); $\mathrm{TL}, \mathrm{BB}, \mathrm{CF}$, and RW (human tissue). The project was supervised by JR, with assistance from TH (TEM), JI (mouse perfusion), TL (human tissue), and CR (PU.1 knockout). The manuscript was written by SSG, $\mathrm{TH}$, and JR, with input from all authors.

Open Access This article is distributed under the terms of the Creative Commons Attribution 4.0 International License (http://creativeco mmons.org/licenses/by/4.0/), which permits unrestricted use, distribution, and reproduction in any medium, provided you give appropriate credit to the original author(s) and the source, provide a link to the Creative Commons license, and indicate if changes were made.

\section{References}

1. Ahn JH, Cho H, Kim J-H, Kim SH, Ham J-S, Park I et al (2019) Meningeal lymphatic vessels at the skull base drain cerebrospinal fluid. Nature 572:62-66. https://doi.org/10.1038/s4158 6-019-1419-5

2. Anderson KL, Smith KA, Conners K, McKercher SR, Maki RA, Torbett BE (1998) Myeloid development is selectively disrupted in PU.1 null mice. Blood 91:3702-3710

3. Andrews WD, Davidson K, Tamamaki N, Ruhrberg C, Parnavelas JG (2016) Altered proliferative ability of neuronal progenitors in PlexinA1 mutant mice. J Comp Neurol 524:518-534. https://doi. org/10.1002/cne.23806

4. Antila S, Karaman S, Nurmi H, Airavaara M, Voutilainen MH, Mathivet T et al (2017) Development and plasticity of meningeal lymphatic vessels. J Exp Med 214:3645. https://doi.org/10.1084/ jem.20170391

5. Aspelund A, Antila S, Proulx ST, Karlsen TV, Karaman S, Detmar $M$ et al (2015) A dural lymphatic vascular system that drains brain interstitial fluid and macromolecules. J Exp Med 212:991-999. https://doi.org/10.1084/jem.20142290

6. Athamna A, Ofek I, Keisari Y, Markowitz S, Dutton GGS, Sharon N (1991) Lectinophagocytosis of encapsulated Klebsiella pneumoniae mediated by surface lectins of guinea pig alveolar macrophages and human monocyte-derived macrophages. Infect Immun 59:1673-1682

7. van de Beek D, de Gans J, Spanjaard L, Weisfelt M, Reitsma JB, Vermeulen M (2004) Clinical features and prognostic factors in adults with bacterial meningitis. N Engl J Med 351:1849-1859. https://doi.org/10.1056/NEJMoa040845

8. Bei Y, Wang F, Yang C, Xiao J (2015) Telocytes in regenerative medicine. J Cell Mol Med 19:1441-1454. https://doi.org/10.1111/ jcmm.12594

9. Bei Y, Zhou Q, Fu S, Lv D, Chen P, Chen Y et al (2015) Cardiac telocytes and fibroblasts in primary culture: different morphologies and immunophenotypes. PLoS One. https://doi.org/10.1371/ journal.pone.0115991 
10. Bifari F, Berton V, Pino A, Kusalo M, Malpeli G, Di Chio M et al (2015) Meninges harbor cells expressing neural precursor markers during development and adulthood. Front Cell Neurosci 9:383. https://doi.org/10.3389/fncel.2015.00383

11. Bower NI, Koltowska K, Pichol-Thievend C, Virshup I, Paterson S, Lagendijk AK et al (2017) Mural lymphatic endothelial cells regulate meningeal angiogenesis in the zebrafish. Nat Neurosci 20:774-783. https://doi.org/10.1038/nn.4558

12. Brat DJ (2018) Normal brain histopathology. In: Brat JD, Perry A (eds) Practical surgical neuropathology: a diagnostic approach. Elsevier, Amsterdam, pp 19-37

13. Chen J, He J, Ni R, Yang Q, Zhang Y, Luo L (2019) Cerebrovascular injuries induce lymphatic invasion into brain parenchyma to guide vascular regeneration in zebrafish. Dev Cell. https:// doi.org/10.1016/j.devcel.2019.03.022

14. Choi SR, Howell OW, Carassiti D, Magliozzi R, Gveric D, Muraro PA et al (2012) Meningeal inflammation plays a role in the pathology of primary progressive multiple sclerosis. Brain 135:2925-2937. https://doi.org/10.1093/brain/aws189

15. Creţoiu SM, Creţoiu D, Popescu LM (2012) Human myometrium-the ultrastructural 3D network of telocytes. J Cell Mol Med 16:2844-2949. https://doi.org/10.111 1/j.1582-4934.2012.01651.x

16. Cretoiu SM, Popescu LM (2014) Telocytes revisited. Biomol Concepts 5:353-369. https://doi.org/10.1515/bmc-2014-0029

17. Gazi U, Martinez-Pomares L (2009) Influence of the mannose receptor in host immune responses. Immunobiology 214:554-561. https://doi.org/10.1016/j.imbio.2008.11.004

18. Goldmann T, Wieghofer P, Jordão M, Prutek F, Hagemeyer N, Frenzel K et al (2016) Origin, fate and dynamics of macrophages at central nervous system interfaces. Nat Immunol 17:797-805. https://doi.org/10.1038/ni.3423

19. Hamano T, Yoshimura M, Yamazaki T, Shinkai Y, Yanagisawa K, Kuriyama M et al (1997) Amyloid $\beta$-protein (A $\beta$ ) accumulation in the leptomeninges during aging and in Alzheimer disease. J Neuropathol Exp Neurol 56:922-932. https://doi.org/10.1097/00005 072-199708000-00010

20. Hawkes CA, McLaurin J (2009) Selective targeting of perivascular macrophages for clearance of -amyloid in cerebral amyloid angiopathy. Proc Natl Acad Sci 106:1261-1266. https://doi. org/10.1073/pnas.0805453106

21. Heidari M, Johnstone DM, Bassett B, Graham RM, Chua ACG, House MJ et al (2016) Brain iron accumulation affects myelinrelated molecular systems implicated in a rare neurogenetic disease family with neuropsychiatric features. Mol Psychiatry 21:1599-1607

22. Hogan BM, Bos FL, Bussmann J, Witte M, Chi NC, Duckers HJ et al (2009) ccbe 1 is required for embryonic lymphangiogenesis and venous sprouting. Nat Genet 41:396-398

23. Hsu M, Rayasam A, Kijak JA, Choi YH, Harding JS, Marcus SA et al (2019) Neuroinflammation-induced lymphangiogenesis near the cribriform plate contributes to drainage of CNS-derived antigens and immune cells. Nat Commun. https://doi.org/10.1038/ s41467-018-08163-0

24. Hunter MC, Teijeira A, Halin C (2016) T cell trafficking through lymphatic vessels. Front Immunol. https://doi.org/10.3389/fimmu .2016 .00613

25. Iliff JJ, Wang M, Liao Y, Plogg BA, Peng W, Gundersen GA et al (2012) A paravascular pathway facilitates CSF flow through the brain parenchyma and the clearance of interstitial solutes, including amyloid beta. Sci Transl Med 4:147

26. van Impel A, Zhao Z, Hermkens DMA, Roukens MG, Fischer JC, Peterson-Maduro J et al (2014) Divergence of zebrafish and mouse lymphatic cell fate specification pathways. Development 141:1228-1238. https://doi.org/10.1242/dev.105031
27. Jackson DG (2019) Leucocyte trafficking via the lymphatic vasculature- mechanisms and consequences. Front Immunol. https:// doi.org/10.3389/fimmu.2019.00471

28. Johnston M, Zakharov A, Papaiconomou C, Salmasi G, Armstrong D (2004) Evidence of connections between cerebrospinal fluid and nasal lymphatic vessels in humans, non-human primates and other mammalian species. Cerebrospinal Fluid Res 1:2-15

29. Jordão MJC, Sankowski R, Brendecke SM, Sagar, Locatelli G, Tai YH et al (2019) Single-cell profiling identifies myeloid cell subsets with distinct fates during neuroinflammation. Science (80). https://doi.org/10.1126/science.aat7554

30. Karaman S, Hollmén M, Robciuc MR, Alitalo A, Nurmi H, Morf $B$ et al (2015) Blockade of VEGF-C and VEGF-D modulates adipose tissue inflammation and improves metabolic parameters under high-fat diet. Mol Metab 4:93-105. https://doi. org/10.1016/j.molmet.2014.11.006

31. Kida S, Pantazis A, Weller RO (1993) CSF drains directly from the subarachnoid space into nasal lymphatics in the rat-anatomy, histology and immunological significance. Neuropathol Appl Neurobiol 19:480-488

32. Lashley T, Rohrer JD, Bandopadhyay R, Fry C, Ahmed Z, Isaacs AM et al (2011) A comparative clinical, pathological, biochemi$\mathrm{cal}$ and genetic study of fused in sarcoma proteinopathies. Brain 134:2548-2564. https://doi.org/10.1093/brain/awr160

33. Lauter G, Söll I, Hauptmann G (2011) Two-color fluorescent in situ hybridization in the embryonic zebrafish brain using differential detection systems. BMC Dev Biol. https://doi. org/10.1186/1471-213X-11-43

34. Lein ES, Hawrylycz MJ, Ao N, Ayres M, Bensinger A, Bernard A et al (2007) Genome-wide atlas of gene expression in the adult mouse brain. Nature 445:168-176. https://doi.org/10.1038/natur e05453

35. Lerner TR, Carvalho-Wodarz CDS, Repnik U, Russell MRG, Borel S, DIedrich CR et al (2016) Lymphatic endothelial cells are a replicative niche for Mycobacterium tuberculosis. J Clin Invest 126:1093-1108. https://doi.org/10.1172/JCI83379

36. van Lessen M, Shibata-Germanos S, van Impel A, Hawkins TA, Rihel J, Schulte-Merker S (2017) Intracellular uptake of macromolecules by brain lymphatic endothelial cells during zebrafish embryonic development. Elife 6:1-24. https://doi.org/10.7554/ eLife. 25932

37. Louveau A, Herz J, Alme MN, Salvador AF, Dong MQ, Viar KE et al (2018) CNS lymphatic drainage and neuroinflammation are regulated by meningeal lymphatic vasculature. Nat Neurosci 21:1380-1391. https://doi.org/10.1038/s41593-018-0227-9

38. Louveau A, Smirnov I, Keyes TJ, Eccles JD, Rouhani SJ, Peske JD et al (2015) Structural and functional features of central nervous system lymphatic vessels. Nature 523:337-341. https://doi. org/10.1038/nature14432

39. Ma Q, Ineichen BV, Detmar M, Proulx ST (2017) Outflow of cerebrospinal fluid is predominantly through lymphatic vessels and is reduced in aged mice. Nat Commun. https://doi.org/10.1038/ s41467-017-01484-6

40. Manta L, Rusu MC, Pop F (2018) What podoplanin tells us about cells with telopodes. Ann Anat 218:124-128. https://doi. org/10.1016/j.aanat.2018.04.001

41. Marttila-Ichihara F, Turja R, Miiluniemi M, Karikoski M, Maksimow M, Niemelä J et al (2008) Macrophage mannose receptor on lymphatics controls cell trafficking. Blood 112:64-72. https:// doi.org/10.1182/blood-2007-10-118984

42. Mato M, Ookawara S, Sakamoto A, Aikawa E, Ogawa T, Mitsuhashi U et al (1996) Involvement of specific macrophage-lineage cells surrounding arterioles in barrier and scavenger function in brain cortex. Proc Natl Acad Sci USA 93:3269-3274. https://doi. org/10.1073/pnas.93.8.3269 
43. McKercher SR, Torbett BE, Anderson KL, Henkel GW, Vestal DJ, Baribault $\mathrm{H}$ et al (1996) Targeted disruption of the PU.1 gene results in multiple hematopoietic abnormalities. EMBO J 15:5647-5658

44. Da Mesquita S, Louveau A, Vaccari A, Smirnov I, Cornelison RC, Kingsmore KM et al (2018) Functional aspects of meningeal lymphatics in ageing and Alzheimer's disease. Nature 560:185-191. https://doi.org/10.1038/s41586-018-0368-8

45. Norwood JN, Zhang Q, Card D, Craine A, Ryan TM, Drew PJ (2019) Anatomical basis and physiological role of cerebrospinal fluid transport through the murine cribriform plate. Elife. https:// doi.org/10.7554/eLife.44278

46. Popescu BO, Gherghiceanu M, Kostin S, Ceafalan L, Popescu LM (2012) Telocytes in meninges and choroid plexus. Neurosci Lett 516:265-269. https://doi.org/10.1016/J.NEULET.2012.04.006

47. Popescu LM, Ciontea SM, Cretoiu DC (2007) Interstitial Cajallike cells in human uterus and fallopian tube. Ann N Y Acad Sci 1101:139-165. https://doi.org/10.1196/annals.1389.022

48. Popescu LM, Gherghiceanu M, Manole CG, Faussone-Pellegrini MS (2009) Cardiac renewing: interstitial Cajal-like cells nurse cardiomyocyte progenitors in epicardial stem cell niches. J Cell Mol Med 13:866-886. https://doi.org/10.111 1/j.1582-4934.2009.00758.x

49. Porcaro I, Vidal M, Jouvert S, Stahl PD, Giaimis J (2003) Mannose receptor contribution to Candida albicans phagocytosis by murine E-clone J774 macrophages. J Leukoc Biol 74:206-215. https://doi.org/10.1189/jlb.1202608

50. Reading PC, Miller JL, Anders EM (2000) Involvement of the mannose receptor in infection of macrophages by influenza virus. J Virol 74:5190-5197. https://doi.org/10.1128/ jvi.74.11.5190-5197.2000

51. Rua R, McGavern DB (2018) Advances in meningeal immunity. Trends Mol Med 6:542-559. https://doi.org/10.1016/j.molme d.2018.04.003

52. Rusu MC, Pop F, Hostiuc S, Curca GC, Jianu AM, Paduraru D (2012) Telocytes form networks in normal cardiac tissues. Histol Histopathol 27:807-816

53. Schläger C, Körner H, Krueger M, Vidoli S, Haberl M, Mielke D et al (2016) Effector T-cell trafficking between the leptomeninges and the cerebrospinal fluid. Nature 530:349

54. Schlesinger LS (1993) Macrophage phagocytosis of virulent but not attenuated strains of Mycobacterium tuberculosis is mediated by mannose receptors in addition to complement receptors. J Immunol 150:2920-2930

55. Shinkai Y, Morishima-Kawashima M, Ihara Y, Yoshimura M, Shimada H, Ito $Y$ et al (1997) Amyloid $\beta$-protein deposition in the leptomeninges and cerebral cortex. Ann Neurol 42:899-908. https://doi.org/10.1002/ana.410420612

56. Stahl PD, Wileman TE, Diment S, Shepherd VL (1984) Mannosespecific oligosaccharide recognition by mononuclear phagocytes. Biol Cell 51:215-218. https://doi.org/10.1111/j.1768-322X.1984. tb00301.x

57. Subramanian K, Neill DR, Malak HA, Spelmink L, Khandaker S, Dalla Libera Marchiori G et al (2019) Pneumolysin binds to the mannose receptor $\mathrm{C}$ type 1 (MRC-1) leading to anti-inflammatory responses and enhanced pneumococcal survival. Nat Microbiol 4:62-70. https://doi.org/10.1038/s41564-018-0280-x

58. Takeda S, Yamazaki K, Miyakawa T, Onda K (2017) Cerebral amyloid angiopathy initially occurs in the meningeal vessels. Neuropathology 37:502-508. https://doi.org/10.1111/neup.12403

59. Tamamaki N, Yanagawa Y, Tomioka R, Miyazaki JI, Obata K, Kaneko T (2003) Green fluorescent protein expression and colocalization with calretinin, parvalbumin, and somatostatin in the GAD67-GFP knock-in mouse. J Comp Neurol 467:60-79. https://doi.org/10.1002/cne.10905

60. Tomlinson JJ, Shutinoski B, Dong L, Meng F, Elleithy D, Lengacher NA et al (2017) Holocranohistochemistry enables the visualization of $\alpha$-synuclein expression in the murine olfactory system and discovery of its systemic anti-microbial effects. J Neural Transm 124:721-738. https://doi.org/10.1007/s00702-017-1726-7

61. Tomooka M, Kaji C, Kojima H, Sawa Y (2013) Distribution of Podoplanin-Expressing Cells in the Mouse Nervous Systems. Acta Histochem Cytochem 46:171-177. https://doi.org/10.1267/ ahc. 13035

62. Upton ML, Weller RO (2009) The morphology of cerebrospinal fluid drainage pathways in human arachnoid granulations. J Neurosurg 63:867-875. https://doi.org/10.3171/jns.1985.63.6.0867

63. Vandenabeele F, Creemers J, Lambrichts I (1996) Ultrastructure of the human spinal arachnoid mater and dura mater. J Anat 189 (Pt 2:417-430

64. Vannucchi MG, Traini C, Manetti M, Ibba-Manneschi L, Faussone-Pellegrini MS (2013) Telocytes express PDGFR $\alpha$ in the human gastrointestinal tract. J Cell Mol Med 17:1099-1108. https ://doi.org/10.1111/jcmm.12134

65. Varga I, Kyselovič J, Danišovič L, Gálfiová P, Kachlík D, Polák Š et al (2019) Recently discovered interstitial cells termed telocytes: distinguishing cell-biological and histological facts from fictions. Biologia (Bratisl) 74:195-203. https://doi.org/10.2478/ s11756-018-0162-y

66. Venero Galanternik M, Castranova D, Gore AV, Blewett NH, Jung HM, Stratman AN et al (2017) A novel perivascular cell population in the zebrafish brain. Elife 6:1-28. https://doi.org/10.7554/ eLife. 24369

67. Voelz K, Gratacap RL, Wheeler RT (2015) A zebrafish larval model reveals early tissue-specific innate immune responses to Mucor circinelloides. Dis Model Mech 8:1375-1388. https://doi. org/10.1242/dmm.019992

68. Weller RO, Massey A, Newman TA, Hutchings M, Kuo YM, Roher AE (1998) Cerebral amyloid angiopathy: amyloid beta accumulates in putative interstitial fluid drainage pathways in Alzheimer's disease. Am J Pathol 153:725-733

69. Wilting J, Papoutsi M, Christ B, Nicolaides KH, Von Kaisenberg CS, Borges J et al (2002) The transcription factor Prox 1 is a marker for lymphatic endothelial cells in normal and diseased human tissues. FASEB J 16:1271-1273. https://doi.org/10.1096/ f. 01-1010fje

70. Yasuda K, Cline C, Vogel P, Onciu M, Fatima S, Sorrentino BP et al (2013) Drug transporters on arachnoid barrier cells contribute to the blood-cerebrospinal fluid barrier. Drug Metab Dispos 41:923-931. https://doi.org/10.1124/dmd.112.050344

71. Zhang Y, Lu Y, Ma L, Cao X, Xiao J, Chen J et al (2014) Activation of vascular endothelial growth factor receptor-3 in macrophages restrains TLR4-NF- $\mathrm{KB}$ signaling and protects against endotoxin shock. Immunity 40:501-514. https://doi.org/10.1016/j. immuni.2014.01.013

Publisher's Note Springer Nature remains neutral with regard to jurisdictional claims in published maps and institutional affiliations. 